\title{
O GLOSSÁRIO MALAIO dO CAVALEIRO PIGAFETTA
}

\author{
Luís Filipe F. R. Thomaz \\ Universidade Nova de Lisboa / Universidade Católica Portuguesa
}

Resumo: Dos numerosos textos que relatam a primeira volta ao mundo é, de facto, o de Antonio Pigafetta o mais completo, rigoroso e fidedigno. Entre as suas peculiaridades conta-se a de incluir pequenos glossários de quatro diferentes línguas de povos com que os viajantes toparam: um, de oito vocábulos apenas, dos índios brasileiros da região de Guanabara; outro, um pouco mais desenvolvido, dos «gigantes patagões» vizinhos do Estreito de Magalhães; um terceiro da língua austronésica dos nativos da Cebu, nas atuais Filipinas; e, finalmente, um extenso glossário de 426 termos do malaio, usado em toda a Insulíndia como língua veicular e de comércio. Desenvolve-se aqui a notação pormenorizada deste glossário malaio.

Palavras-chave: Antonio Pigafetta; primeira volta ao mundo; literatura de viagens renascentista; glossário malaio; século xvI.

\section{The Malaysian Glossary by the Knight Pigafetta}

АвsтRACt: Of the many texts that narrate the first circumvention of the globe, it is, in fact, Antonio Pigafetta's that is the most complete, rigorous, and reliable. Among its peculiarities is the inclusion of small glossaries for four different languages from tribes the travellers met. One is comprised of only eight words, from indigenous people of Brazil in the region of Guanabara; another, somewhat more developed, is from the "Patagonian Giants", neighbouring the Strait of Magellan; the third is an Austronesian language of the natives of Cebu, in what is now the Philippines; and, finally, there is an extensive glossary of $426 \mathrm{Ma}$ lay terms used throughout Insulindia, or present-day South-East Asea, as a lingua franca or trading language. The following is a detailed notation for the Malayan glossary.

KeYwords: Antonio Pigafetta; first circumvention of the globe; Renaissance travel writing; Malayan glossary; $16^{\text {th }}$ century.

À memória de Paramita Abdurrachman, saudosa amiga que a morte ceifou, a quem fico devendo muito do que sei sobre Maluco.

Embora o primeiro relato da circum-navegação do Globo por Fernão de Magalhães e Sebastião Delcano a ser dado à estampa, logo em I522, seja a Epísto-

Thomaz, Luís Filipe F. R. (2019). «O glossário malaio do cavaleiro Pigafetta». Abriu, 8, 99-133. ISSN: 2014-8526. e-ISSN: 2014-8534. DOI: I0.1344/abriu2019.8.6. Received: I4/12/2018. Accepted: $14 / 1 / 2019$. 
la de Maximiliano Transilvano, secretário de Carlos V, ao cardeal arcebispo de Salisburgo, o mais célebre de todos eles é, e a justo título, o do patrício vicentino e cavaleiro hospitalário Antonio Pigafetta, publicado em tradução francesa abreviada entre 1526 e i536, e depois retrovertido em italiano. O texto original andou perdido muito tempo, até ser em 1797 descoberto na Biblioteca Ambrosiana de Milão e finalmente publicado.

Dos numerosos textos que relatam a primeira volta ao mundo é, de facto, o de Pigafetta o mais completo, rigoroso e fidedigno. Entre as suas peculiaridades conta-se a de incluir pequenos glossários de quatro diferentes línguas de povos com que os viajantes toparam: um, de oito vocábulos apenas, dos popoli del Verzin, ou seja, dos índios brasileiros da região de Guanabara; outro, um pouco mais desenvolvido, dos «gigantes patagões» vizinhos do Estreito de Magalhães; um terceiro da língua austronésica dos nativos da Cebu, nas atuais Filipinas; e, finalmente, um extenso glossário de 426 termos do idioma em que os moiros comunicavam em Maluco e regiões vizinhas, que não é como se poderia imaginar, uma das línguas papuas faladas no arquipélago, mas o malaio, usado em toda a Insulíndia como língua veicular e de comércio.

$\mathrm{Na}$ falta de documentos escritos torna-se impossível determinar quando começou a língua malaia a ser empregue em Maluco: é provável que o seu uso remonte à hegemonia marítima do reino malaio de Seri Wijaya, Śrî Vijaya ou Çrî Vijaya, no sueste de Samatra, entre os séculos VII e XI; mas também pode ser que só se tenha definitivamente firmado como língua veicular na época da hegemonia do sultanado de Malaca, no século XV, sendo assim a sua difusão concomitante da do islão. ${ }^{1}$ Há algum tempo foi descoberta junto à Laguna de Bay, perto de Manila, nas Filipinas, uma inscrição em malaio antigo, datada de 900 A. D. (Postma 1992). ${ }^{2}$ Por outro lado um recente estudo dos empréstimos vocabulares malaios no tagalo, língua falada na zona central de Lução (Adelaar, 1994), veio demonstrar que esses vocábulos foram importados numa época muito antiga, pois preservam — nomeadamante os de origem sanscrítica -

' Hoje, a maioria dos habitantes da área de Maluco Setentrional (Maluku Utara) entende o ternatês, que funciona assim como língua veicular ao lado do malaio (Andili r9781979); tal uso está atestado desde c. 1570, mas é de supor que derive da hegemonia política de Ternate, que não remonta senão a finais do século Xv.

2 Pode ver-se o texto da inscrição, com tradução em inglês e notas históricas em Munoz (2006). Agradeço ao meu velho amigo e colega Pierre-Yves Manguin ter-me chamado a atenção quer para esta obra quer para a seguinte. 
traços fonéticos arcaizantes, que desapareceram do malaio moderno. Estes factos vêm provar que o malaio foi utilizado como língua de comércio na Insulíndia oriental desde o período de Seri Wijaya e corroboram a tese de que terá sido nessa época que foi introduzido em Maluco; sem embargo de aí não terem por ora sido achados testemunhos escritos do seu uso anteriores às cartas do sultão de Ternate Abu Hayat a El-rei de Portugal, que doutra feita publicámos (Thomaz 2003). Como o dialeto malaio falado na ilha de Bachão não é idêntico ao malaio usado como língua veicular nas outras ilhas, pode admitir-se que representem duas camadas diferentes, remontando aquele ao período de Seri Wijaya, e este ao da hegemonia de Malaca. É impossível determiná-lo ao certo, pois não se acharam até hoje em Maluco inscrições no silabário de origem indiana usado em Seri Wijaya nem em nenhuma das escritas afins. Quanto à escrita jawi (alfabeto árabe adaptado à fonética do malaio), não há dúvidas de que foi trazida de Malaca e se difundiu com o islão em finais do século XV.

Para a difusão do malaio como língua-franca da região muito deve ter contribuído a extrema fragmentação linguística do pequeno arquipélago, onde — entre as ilhas de Ternate, Tidore, Motir, Maquiém, Bachão e Halmaheira, as que no século XVI eram já designadas por Maluco — se falam pelo menos 26 idiomas distintos, pertencendo 7 à família austronésica e classificando-se os outros I9 como papuas (Cribb 2000: 34). O recurso a um idioma veicular era uma necessidade. É apenas desde 1999 que a região de Maluco lato sensu forma duas províncias da República Indonésia: Maluku Utara ou Maluco Setentrional, que engloba as ilhas acima nomeadas, e Maluku tout court, que compreende as de Buro, Ceirão e Amboino, e todas as demais que jazem entre Celebes, Timor e a Nova Guiné. Foram, por conseguinte, ainda computadas como uma única província no censo de i990, que mostrou ser uma das zonas do país onde o malaio é mais falado: mais de $80 \%$ da população total. Profundo é o contraste com o que se passa, por exemplo, em Java Central, onde a língua local, o jau ou javanês, conserva os seus direitos, e o malaio (oficialmente designado por bahasa indonesia, «língua indonésia») era ainda em I990 fluentemente falado por menos de metade da população (Cribb 2000: 37).3

3 Além de Maluco (Maluku) as únicas províncias em que a percentagem de indivíduos fluentes em malaio excedia os $80 \%$ eram as de Celebes Norte (Sulawesi Utara), a de Riau em Samatra, berço do malaio, e a de Samatra Oeste (Sumatera Barat), correspondente à região de Menancabo ou Minangkabau, contígua à precedente, onde se fala o menancabo, língua que grosso modo está para o malaio como o português para o castelhano. 
Não é de estranhar, portanto, que a amostra lingüística recolhida pelo cavaleiro Pigafetta em Tidor corresponda ao malaio. Pigafetta era dotado não só de uma grande curiosidade como de um excelente ouvido, de modo que as suas transcrições são de uma maneira geral facilmente identificáveis, embora aqui e além ocorram por vezes pequenas distorções semânticas. Há que notar contudo que, embora inserido no relato de Pigafetta na parte referente a Maluco, parte dos vocábulos que constam do seu glossário devem ter sido recolhidos em Brunei, onde já depois da morte de Magalhães o que restava da frota fez escala, como o demonstram alguns rasgos dialetais característicos. Outros traços dialetais apontam para Java e devem corresponder a vocábulos fornecidos por tripulantes dos navios, quiçá oriundos da região. O mesmo se diga de alguns vocábulos tagalos que aparecem misturados aos malaios. Pode concluir-se desta heterogeneidade dialetal que o informador principal do cavaleiro Pigafetta não foi Henrique, o escravo malaio de Magalhães, que era oriundo de Samatra, que aliás desapareceu nas Filipinas, logo após a morte de seu amo em Mactán a 27 de Abril de I521. O glossário deve ter sido compilado nos meses subsequentes, durante a visita do que restava da frota a Brunei e a Maluco.

Note-se que o glossário malaio de Pigafetta não é o mais antigo que até nós chegou, pois houve no século XV um autor anónimo ou, talvez mais provavelmente, vários que coligiram em Malaca uma lista de 482 termos chineses com seus equivalentes em malaio, aproximadamente transcritos em caracteres chineses na pronúncia mandarina (Edwards e Blagden I93I).4

O uso de coligir ad hoc pequenos glossários dos termos mais usuais em cada língua não é propriamente uma inovação do nosso autor, já que se observa uma vintena de anos mais cedo nos apensos ao Diário da primeira viagem de Vasco da Gama, onde sob o título «esta é a linguagem de Calecut» se inclui uma lista de uns i 80 vocábulos em malabar ou malaiala, a língua dravídica falada em todo o Quêrala. ${ }^{5}$

4 As palavras chinesas que mencionamos no presente artigo vão transcritas segundo o sistema de Wade-Gilles, o mais fonético, embora acompanhadas, sempre que possível, dos caracteres respetivos. A tanscrição representa a pronúncia mandarina; apenas daremos a pronúncia cantonesa nos casos em que esta transcreva mais fielmente os termos malaios corespondentes.

5 Devido à paronímia entre malaio e malaiala, que é meramente ocasional, tem, contudo, sido apresentado por alguns autores mais zelosos da modernização e popularização de terminologia que utilizam como «vocabulário malaio», o que é, evidentemente, um erro 
Não se conhece, contudo, nenhum glossário malaio-português ou português-malaio anterior aos dois que em finais do século XvIII, a instâncias do Dr. António Ribeiro dos Santos, primeiro diretor da Real Biblioteca Pública da Corte (I796-ı8ı6), antecessora da atual Biblioteca Nacional, coligiu Elias José do Valle, tripulante de um navio de comércio que fazia a linha Macau-Malaca (Lonbard e Thomaz I98I). ${ }^{6}$ Tal lacuna não é de estranhar: a maioria dos antigos dicionários de línguas asiáticas que, manuscritos ou impressos, existem nas nossas bibliotecas devem-se aos jesuítas e estes raramente se dedicavam a tentar — pois em regra era em vão — converter muçulmanos, como era o caso dos malaios. É verdade que a Sagrada Congregação de Propaganda Fide veio a imprimir em i63 I na sua tipografia em Roma um Dictionarium malaico-latinum et latino-malaicum cum aliis quam plurimis quae quarta pagina edocebit, compilado por David Haex; há que notar, no entanto, que o livro se não destinava necessariamente aos potenciais apóstolos dos malaios, uma vez que o malaio se usava como língua veicular em todo o Arquipélago, onde havia muitas populações pagãs.

Seja como for, após o glossário de Pigafetta, o vocabulário malaio mais antigo que se conhece é o de Frederick de Houtman, irmão e companheiro de Cornelis de Houtman na primeira viagem holandesa ao Oriente (I595-97), que inclui igualmente um guia de conversação (Lonbard, Arifin e Wibisono i970). Por sumárias que em geral sejam, as obras deste tipo são importantes elementos para se traçar a história da língua; o que, no caso do malaio, está quase inteiramente por fazer.

Estes glossários são por outro lado interessantes para a história do quotidiano e para a das mentalidades, pois permitem-nos entrever a multiplicidade de escopos com que foram compilados. Pela importância que muitos, a despeito do seu caráter elementar, atribuem ao vocabulário referente ao sexo, deixam-se adivinhar objetivos muito diversos, quer do comércio, quer da missionação...7

crasso, já que não há entre um e outro idioma (autronésio ou malaio-polinésico um, dravídico o outro) qualquer parentesco ou semelhança.

${ }^{6}$ Aparentemente o glossário malaio-português não estava ainda então catalogado, pelo que nos passou despercebido; reportámo-nos por conseguinte apenas ao recíproco, português-malaio.

7 Assim no glossário malabar que acompanha o Diário da viagem de Vasco da Gama, onde uma mão púdica posterior se dedicou a raiar os termos que, grosso modo a partir da 
Pigafetta não é exceção, embora seja mais discreto e mais sucinto no apresentar das cousas: não só apenas inclui três vocábulos respeitantes ao sexo, como lhes alude assaz obliquamente: por membro designa o pénis (o que apenas resulta claro do correspondente malaio, que permite identificar qual é o «membro» em questão), por natura delle donne a vagina, e por usare con esse, «usar delas» (scilicet, «delle donne») o comércio carnal.

O seu glossário foi estudado já por diversos autores; ater-nos-emos sobretudo ao estudo feito pelo saudoso erudito e poliglota italiano Alessandro Bausani (1960), ${ }^{8}$ de longe o mais completo e mais exato. Para comodidade do leitor reduzimo-lo a um quadro, em que os elementos dados por Pigafetta vão sobre fundo sombreado e sobre fundo branco os intercalados por nós; estes resumem-se à tradução portuguesa de cada vocábulo italiano ${ }^{9}$ e à transcrição do termo malaio correspondente na éjaan baru, «nova ortografia», adotada em I972 por acordo ortogtáfico entre os quatro países em que o malaio é língua oficial: Indonésia, Malásia, Brunei e Cingapura. ${ }^{10}$ Nesse sistema apenas há a notar o seguinte:

- o c nota uma africada palatal surda correspondente ao ch transmontano ou castelhano $(=t x)$;

- o dígrafo ng indica uma nasal velar semelhante às que ocorrem no vocábulo inglês singing;

Contra-Reforma, começaram a ser tidos por grosseiros — sem contudo impedir que, sob o traço, se possam ainda ler «caralho» (de *araculum, «pauzinho, varinha», diminutivo do ter-

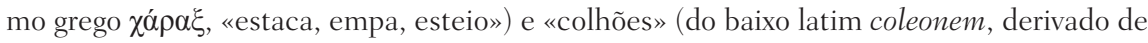
coleus, «bisalho, saco de coiro») e, com cuidado e atenção, talvez ainda outros vocábulos congéneres. Quanto a «cona» (do latim connum, com o mesmo sentido, já considerado grosseiro e por isso só atestado em graffiti e textos satíricos, passado ao género feminino em português, mas não nas demais línguas românicas, por associação lógica ao sexo feminino), aparece, ao lado dos dois mesmíssimos termos acima mencionados, no glossário malaio de Elias José do Vale (cuja ordem é apenas aproximadamente alfabética) logo ao começo da letra C.

8 Agradeço à minha colega e velha amiga Claudine Salmon ter-me facultado cópia deste artigo, aparecido numa época em que andava ainda longe destas lides.

9 Há que notar que Pigafetta não escreve em toscano ou italiano literário, mas numa mescla de toscano, véneto e castelhano; certas formas dialectais apenas se tornam compreensíveis através do seu significado malaio.

10 Na realidade, embora com pequenas variações dialectais, de amplitude comparável às que separam o português do Brasil do de Portugal, trata-se de uma só língua, ainda que na Indonésia seja designada por bahasa indonesia, na Malásia por bahasa malaysia e nos outros dois países por bahasa melayu, a designação tradicional. 
- a sequência 'nasal velar + oclusiva gutural', idêntica à que ocorre em português em banco ou em manga, é notada por ngk e ngg;

- a nasal palatal correspondente ao fonema notado por $n h$ em português, é notada por $n y$;

- os fonemas árabes $\dot{\tau}$ ( $\underline{k h}$ ou $\underline{h}$, que soa como a jota castelhana) e ش ( $\underline{s h}$ ou $\check{s}$, que soa como $x$ em galego ou português), na pronúncia corrente muitas vezes reduzidos aos fonemas malaios mais próximos, $k$ e $s$, são respectivamente notados po kh e sy;

- embora não faça parte da grafia oficial, apenas se utilizando em livros didáticos e dicionários, assinalámos a distinção entre o e pepet (e mudo, aproximadamente idêntico ao que soa em português em de ou que) e o é aberto, que marcámos com acento gráfico. Pigafetta nota regularmente o primeiro por -a-, o que hoje corresponde sobretudo à pronúncia banjar, i.e., das cidades malaias do sul de Bornéu.

Há que notar que o manuscrito de Pigafetta reencontrado em i797 é apógrafo, tendo o manuscrito autógrafo sido por ele entregue a Carlos V mas tendo desaparecido em seguida; é por tal motivo que na transcrição dos termos malaios há muitas aparentes discrepâncias que na realidade são meros erros de copista, nomeadamente muitas confusões entre $n$ e $u$, entre $n u$ e $m i$, etc. Com base no glossário italiano-malaio (não traduzido em francês) da antiga versão francesa do texto de Pigafetta, de que existem três manuscritos e uma edição impressa (entre 1526 e 1536), é possível corrigir, como faz Bausani, a quem seguimos, alguns dos erros de copista do manuscrito da Biblioteca Ambrosiana de Milão. Já a transcrição de numerosos $r r$ por $l l$ parece antes corresponder a uma pronúncia dialetal, comum a diversos falares das Filipinas, Celebes, e certas zonas de Maluco. Marcámos com um A os empréstimos árabes, com um $S$ os termos de origem sanscrítica, com um $T$ os de origem tâmul e com um $P$ os de origem persa. Os problemas levantados por alguns termos (sobretudo divergências entre o sentido do vocábulo italiano e do correspondente termo malaio dado por Pigafetta) são discutidos em nota.

Além do estudo de Bausani, que resolve a mor parte das dificuldades, servimo-nos dos seguintes dicionários:

- R. J. Wilkinson (1944), A Malay-English Dictionary (Romanised), Tokyo, Daitōa Syuppan Kabusiki Kaisya, ano XvıI da era Shôwa [reimp.];

- Dr. Teuku Iskandar (1970), Kamus Dewan di-susun oleh..., Kuala Lampur, Dewan Bahasa dan Pustaka Kementerian Pelajaran; 
- Kamus Besar Bahasa Indonesia (2002), Jacarta, Pusat Bahasa, Department Pendidikan Nasional [ 3 a edição];

- Pierre Larousse (1984), Indonesien Français - Dictionaire General, París, Association Archipel;

- Luigi Santa Maria; Maria Citro (1998), Dizionario Indonesiano-Italiano, Roma, Is.I.A.O.;

- Haji Abdul Rahman bin Yusop (1977), Bahasa Malaysia-English / English-Bahasa Malaysia, Londres; Glasgow, Collins;

- Giacomo Devoto; Gian Carlo Oli (I980), Dizionario della Lingua Italiana, Florença, Dizionari Le Monnier;

- Farida Soermargono; Winarsih Arifin (199I), Dictionaire Français Indonésien - Kamus Perancis-Indonesia, París, Association Archipel;

- Darrell T. Tryon (dir.) (I995), Comparative Austronesian Dictionary: an introduction to Austronesian studies, Berlín; Nova York, Moton de Gruyter, 5 vols.;

- V. Arnaud, H. Campagnolo, et al. (1997), Lexique thématique plurilingue de trente-six langues et dialectes d'Asie du Sud-Est Insulaire, París; Montréal, L'Harmattan, 2 vols.;

- Elinor Clark Horne (1974), Javanese-English Dictionary, Yale, Yale University Press;

- P. J. Zoetmulder (1982), Old Javanese-English Dictionary, Leida, KITLV, 2 vols.;

- Carl R. Galvez Rubino (2005), Tagalog-English / English-Tagalog (Pilipino) Dictionary, Nova York, Hippocrene Books;

- Manuel Patrício Mendes (1935), Dicionário Tétum-Português, Macau, Tipografia Mercantil de N. T. Fernandes \& Filhos Ltda;

- Luís Costa (2000), Dicionário de Tétum-Português, Lisboa, Edições Colibri; Faculdade de Letras da Universidade de Lisboa;

- Manuel Maria Alves da Silva (1905), Diccionario Portuguez-Galoli, Macau, Typographia Mercantil.

Para a identificação botânica das plantas mencionadas servimo-nos especialmente de:

- D. J. Mabberley (1997), The Plant-Book. A portable dictionary of the vascular plants, Cambridge, Cambridge University Press;

- I. H. Burkill (1935), A dictionary of the Economic Products of the Malay Peninsula, Londres, Governments of the Straits Settlements and Federated Malay States by the Crown Agents for the Colonies, 2 vols.;

- http://www.catalogueoflife.org/ (3I/v/20I8, actualizado mensalmente) 
Quanto ao texto de Pigafetta, utilizámos as seguintes edições:

- Xavier de Castro; Jocelyne Hamon; Luís Filipe Thomaz (eds.) (2007), Le Voyage de Magellan (1519-1522). La relation d'Antonio Pigafetta et autres témoignages, París, Chandeigne, 2 vols., (sem os glossários);

- Antonio Pigafetta (1944), La storia del primo viaggio intorno al mondo, Angelo Ginocchieti (ed.), Roma, Editoriale Romana;

- Lagôa, Visconde de (1938), Fernão de Magalhãis (A sua vida e a sua viagem), Lisboa, Seara Nova, 2 vols.

À semelhança dos vocabulários árabes medievais, dos antigos léxicos sanscríticos (como o célebre Amarakoṣa de Amarasiṃha (I839-I845), que data quiçá do século IV) e do léxico chinês-malaio citado acima, os glossários de Pigafetta não estão ordenados por ordem alfabética, mas, embora apenas grosso modo, por ordem lógica: partes do corpo, vegetais, animais, numerais, etc.

\begin{tabular}{llllll}
\hline \multicolumn{7}{c}{$\begin{array}{c}\text { Vocaboli De Questi Popoli Mori } \\
\text { Vocábulos destes povos mouros }\end{array}$} \\
\hline$n^{\circ}$ & Termo italiano & $\begin{array}{l}\text { Tradução } \\
\text { portuguesa }\end{array}$ & $\begin{array}{l}\text { Termo malaio } \\
\text { dado por Pigafetta }\end{array}$ & $\begin{array}{l}\text { Termo malaio em baru } \\
\text { éjaan }\end{array}$ & Nota \\
\hline I & Al suo Yddio & o seu Deus & Allà & Allah $(\mathrm{A})$ & ${ }^{11}$ \\
\hline 2 & $\mathrm{Al}$ christiano & cristão & naceran & nasrani, serani $(\mathrm{A})$ & ${ }^{12}$ \\
\hline 3 & $\mathrm{Al}$ turco & turco & rumío & rumi $(\mathrm{A})$ & ${ }^{13}$ \\
\hline 4 & Al moro musulman & muçulmano & isilam & [orang] islam $(\mathrm{A})$ & \\
\hline 5 & Al gentile & gentio & caphre & kafir, kapir $(\mathrm{A})$ & \\
\hline
\end{tabular}

"Allâh é, evidentemente um empréstimo árabe; em malaio pode dizer-se também Tuhan, lit. «Senhor». Hyang, o antigo termo para «divindade», apenas se usa hoje para os deuses hindus ou pagãos. Sobre os empréstimos vocabulares árabes em malaio pode ver-se (Beg 1977). É interessante notar que já no Glossário chinês-malaio do século xv acima referido, 安刺 An-la é dado como equivalente ao chinês 天 T'ien, «Céu», considerado na China o Ente Supremo.

${ }_{12}$ Lit. «nazareno»; na forma sarani o termo passou ao tétum com o mesmo sentido, de onde a expressão verbal halo sarani, «fazer cristão» usada normalmente em Timor para significar «bàtizar».

${ }^{13}$ Em árabe rûmî significa etimologicamente «romano» e daí «cristão» (uma vez que à época da conquista árabe o Império Romano estava já praticamente todo cristianizado); no 


\begin{tabular}{|c|c|c|c|c|c|}
\hline 6 & $\mathrm{Al}$ sue meschite & mesquita & mischit & masjid $(\mathrm{A})$ & 14 \\
\hline 7 & A li sui preti & os seus sacerdotes & $\begin{array}{l}\text { maulana catip } \\
\text { mudin }\end{array}$ & $\begin{array}{l}\text { maulana, khatib, } \\
\text { modin (A) }\end{array}$ & 15 \\
\hline 8 & A li omini sapienti & homens sabedores & horan pandita & orang pendéta $(\mathrm{S})$ & 16 \\
\hline 9 & $\begin{array}{l}\text { A li homini sui } \\
\text { devoti }\end{array}$ & $\begin{array}{l}\text { os seus homens } \\
\text { devotos }\end{array}$ & mossai & $?$ & 17 \\
\hline IO & A le sue cerimonie & as suas cerimónias & $\begin{array}{l}\text { zambahehan de } \\
\text { alà meschit }\end{array}$ & $\begin{array}{l}\text { sembahyang } \\
\text { di masjid Allah }\end{array}$ & 18 \\
\hline II & Al padre & pai & bapa & bapak & \\
\hline I2 & A la madre & mãe & mama ambui & mama, ibu & \\
\hline 13 & Al figliolo & filho & anach & anak & \\
\hline I4 & Al fratello & irmão & sandala & saudara $(\mathrm{S})$ & 19 \\
\hline
\end{tabular}

Próximo Oriente usa-se ainda hoje para designar os melquitas ou cristãos ortodoxos, de rito bizantino. Contudo, desde que em ro7i os turcos seldjúcidas, após a vitória de Mantzikert sobre o imperador bizantino Romão IV, começaram a penetrar no território outrora romano (onde fundaram o sultanado dito «de Rum», i. e., de Roma, embora tivesse a capital em Konya ou Icónio, no leste da Anatólia) o termo começou a usar-se para designar tanto os turcos como os povos sujeitos ao seu império.

${ }^{14}$ A forma mischit tem aparência de ser um empréstimo português; embora o étimo seja o mesmo, o árabe masjid (nome locativo da $\sqrt{ }$ sajada, «prostrar-se, adorar»), as formas portuguesa, castelhana e italiana antiga têm todo o aspeto de ter sido usurpadas ao antigo árabe numa época em que o ج se pronunciava ainda g (como ainda hoje no Egito) e não $j$ (dj). Já a passagem de $g$ a $q u(=k)$ e de $d$ a t, parece mostrar que o termo passou ao mundo cristão através do arménio (vide Corominas e Pascual 1987-1991, s. v. «mezquita»).

${ }^{15}$ Mawlâna significa literalmente em árabe «nosso mestre»; khațîb é o que faz a khuṭba ou sermão de sexta-feira na mesquita; modin representa a pronúncia malaia do termo árabe mu'adhdhin, «almuadém, muezim, pregoeiro de mesquita».

${ }^{16}$ A forma dada por Pigafetta está mais próxima do étimo sânscrito (paṇịta, «instruído», particípio passado da $\sqrt{ }$ pand- «coligir, acumular») do que a forma modernamente em uso; sobre os empréstimos sanscríticos em malaio, vide Gonda (1998).

${ }^{17}$ Bausani põe duas hipóteses: ou corruptela do árabe mashẩikh, «xeques, anciãos, devotos» ou do árabe muçallî, «orantes, que cumprem o preceito da oração (çalâh)».

${ }_{18}$ Bausani interpreta como sembahyang di dalam masjid, «orar dentro da mesquita»; mas, dada a influência do substrato lingüístico papua no malaio de Maluco, a inversão determinante-determinado (neste caso Allah masjid em vez de masjid Allah) é muito possível e ocorre bastas vezes por exemplo nas cartas de Abu Hayat a El-Rei de Portugal.

19 O étimo sanscrítico significa literalmente «co-uterino», «do mesmo (sa-) útero (uda$r a) »$; mas em malaio o termo usa-se hoje em diversos sentidos que vão de «irmã(o)» a «camarada», passando por «primo, parente»; pode mesmo usar-se como substituto do pronome pessoal da segunda pessoa (kamu, engkau) no sentido de «você». Como Pigafetta nota 


\begin{tabular}{lllll}
\hline I5 & Al fratelle de questo o irmão deste & capatin muiadi & ? \\
\hline I6 & $\mathrm{Al}$ germano & primo & saudala sopopu & saudara sepupu \\
\hline I7 & $\mathrm{Al}$ avo & avô & niny & nénék \\
\hline I8 & $\mathrm{Al}$ socero & sogro & minthua & mentua \\
\hline I9 & $\mathrm{Al}$ genero & genro & minanthu & menantu \\
\hline 20 & $\mathrm{Al}$ homo & homem & horan & orang \\
\hline 21 & A la femina & mulher & poran-poan & perempuan \\
\hline 22 & A li capili & cabelo & lambut & rambut \\
\hline 23 & Al capo & cabeça & capala & kepala $(\mathrm{S})$ \\
\hline 24 & Al fronte & fronte, testa & dai & dahi \\
\hline 25 & Al ochio & olho & matta & mata \\
\hline 26 & A le ciglie & pestanas & quilai & kilai \\
\hline 27 & A le palpebre & pálpebras & cenin & kening \\
\hline 28 & Al nazo & nariz & idon & hidung \\
\hline 29 & A la boca & boca & mulut & mulut \\
\hline 30 & A li labri & lábios & bebere & bibir \\
\hline 3 I & A li denti & dentes & gigi & gigi \\
\hline 32 & A le gengive & gengivas & issi & gusi? isit? \\
\hline 33 & A la lingua & língua & lada & lidah \\
\hline 34 & Al palato & palato, céu da boca & langit & langit \\
\hline & & & & 25 \\
\hline
\end{tabular}

mais abaixo, saudara sepupu significa «primo em primeiro grau»; «primo em segundo grau» diz-se saudara duapupu e assim por diante.

${ }_{20}$ Bausani interpreta kapatid mo jari, «este é o teu irmão» em tagalo, o que é fonética e mesmo historicamente possível, conquanto, como notámos já, a expedição de Magalhães não tenha passado em Lução, onde se fala o tagalo.

${ }^{21}$ Orang significa «pessoa» ou «homem lato sensu»; homem no sentido de «varão» diz -se laki-laki ou lelaki.

22 Ao lado do empréstimo sanscrítico kepala existe em malaio um termo vernáculo, hulu (cf. tétum ulun, tagalo ûlo, sundanês hulu). O Glossário Chinês-Malaio dá 巴刺 pa-la, que corresponde a kepala.

${ }_{23}$ Os dicionários registam este termo mas na acepção de «bobine, anel para enrolar um fio»; segundo Bausani kilai existe em diversos idiomas das Filipinas, mas significa «sobrancelhas» (Tryon I995, 04.4I2). O termo usual para «pestanas» é bulu mata.

24 Kening na realidade significa «sobrancelhas»; o termo usual para «pálpebras» é kelopak mata.

${ }_{25}$ Gusi é o termo mais comum, mas isit é o termo usado em betawi («dialeto de Batávia», i. e. de Jacarta).

${ }_{26}$ Langit significa propriamente «céu»; «céu da boca» diz-se normalmebte langit-langit ou langit-langit mulut. 


\begin{tabular}{|c|c|c|c|c|c|}
\hline 35 & Al mento & queixo & aghai & ajai & 27 \\
\hline 36 & A la barba & barba & ianghut & janggut & \\
\hline 37 & A li mostaqui & bigode & missai & misai & \\
\hline 38 & A la macella & maxila & pipi & pipi & 28 \\
\hline 39 & A le orechie & orelhas & talingha & telinga & \\
\hline 40 & A la golla & garganta & laher & léhér & \\
\hline $4 \mathrm{I}$ & $\mathrm{Al}$ colo & pescoço & tundun & tundun & 29 \\
\hline 42 & A le spale & espáduas & balachan & belakang & $3^{\circ}$ \\
\hline 43 & $\mathrm{Al}$ peto & peito & dada & dada & \\
\hline 44 & Al core & coração & atti & hati & $3^{1}$ \\
\hline 45 & A la mamela & mama, seio & sussu & susu & 32 \\
\hline $4^{6}$ & Al stomacho & estômago & parut & perut & \\
\hline 47 & Al corpo & corpo & tundunbutu & tundun butuh (?) & 33 \\
\hline $4^{8}$ & Al membro & membro [viril] & botto & butuh & \\
\hline 49 & $\begin{array}{l}\text { A la natura } \\
\text { de le donne }\end{array}$ & $\begin{array}{l}\text { natureza das mu- } \\
\text { lheres [vagina] }\end{array}$ & bucchi & puki & \\
\hline 50 & Al uzare com loro & servir-se delas & amput & amput & \\
\hline $5^{\mathrm{I}}$ & A le nalghe & nádegas & buri & buri, burit & 34 \\
\hline 52 & A le coscie & coxas & paha & paha & \\
\hline 53 & A la gamba & pernas & mina & mina (?) & \\
\hline 54 & $\begin{array}{l}\text { Al schinquo } \\
\text { de la gamba }\end{array}$ & canela da perna & tula & tulang & 35 \\
\hline
\end{tabular}

${ }_{27}$ Wilkinson registra ajai como termo para «queixo» no dialeto de Brunei; o termo corrente é dagu.

${ }_{28}$ Pipi não significa exatamente «maxila» (it. mascela), mas «bochecha».

${ }_{29}$ Os dicionários registram o termo tundun mas com o sentido de «monte púbico», mons-veneris.

$3^{\circ}$ Belakang significa propriamente «dorso, costas»; as espáduas chamam-se bahu (do termo sanscrítico que significa «braço») ou pundak.

${ }^{31}$ Hati designa o coração como sede das emoções ou em sentido figurado; em sentido anatómico «coração» é jantung e hati designa o «fígado; no Glossário Chinês-Malaio 亞 ya (cant. a) 的ti é dado como equivalente a «fígado».

32 Susu significa também «leite».

33 Tundun é o termo $\mathrm{n}^{\mathrm{O}}{ }_{4} \mathrm{I}$ e butuh o $\mathrm{n}^{\mathrm{O}} 48$, do que viria o composto a significar «colo do pénis, monte púbico masculino»; mas é possível que butuh seja uma metátese por tubuh, que de facto significa «corpo».

34 Buri é termo dialectal, usado em Java; burit, «traseiro», é de uso mais geral.

35 Em italiano literário stinco della gamba; quanto a tulang, significa «osso» em geral; a tíbia ou canela da perna é normalmente dita tulang kering, lit. «osso seco». 


\begin{tabular}{|c|c|c|c|c|c|}
\hline 55 & A la sua polpa & barriga da perna & tilorehai & telur kaki & $3^{6}$ \\
\hline 56 & $\begin{array}{l}\text { A la cavechia } \\
\text { del pie }\end{array}$ & tornoselo & buculali & buku lali & \\
\hline 57 & Al calcagnia & calcanhar & tumi & tumit & \\
\hline 58 & Al piede & pé & batis & betis & 37 \\
\hline 59 & $\begin{array}{l}\text { A le solle } \\
\text { del piede }\end{array}$ & solas do pé & empahaci & $\begin{array}{l}\text { tapak kaki? empu } \\
\text { kaki? }\end{array}$ & $3^{8}$ \\
\hline 60 & A la ongia & unhas & cuchu & kuku & \\
\hline 6I & Al bracio & braço & langhan & lengan & \\
\hline 62 & $\mathrm{Al}$ gomedo & cotovelo & sichu & siku & \\
\hline 63 & A la mano & mão & tanghan & tangan & \\
\hline 64 & $\begin{array}{l}\text { Al dito grosso } \\
\text { de la mano }\end{array}$ & $\begin{array}{l}\text { dedo grosso da } \\
\text { mão }\end{array}$ & idun tanghan & hidung tangan & 39 \\
\hline 65 & $\mathrm{Al}$ secondo & segundo [dedo] & tungu & tundjuk & $4^{\circ}$ \\
\hline 66 & Al terso & terceiro [dedo] & geri & jari & 41 \\
\hline 67 & $\mathrm{Al}$ carto & quarto [dedo] & mani & manis & \\
\hline 68 & $\mathrm{Al}$ quinto & quinto [dedo] & calinchin & kelingking & \\
\hline 69 & $\mathrm{Al}$ rizo & arroz & bugax & beras & 42 \\
\hline
\end{tabular}

${ }^{6}$ Lit. «ovo da perna», composto que os modernos dicionários não registam.

37 Betis é em rigor a parte inferior da perna; o pé é normalmente designado por kaki. O uso de betis neste sentido é dialectal.

$3^{8}$ A forma corrente é tapak kaki; a forma dada por Pigafetta parece corresponder antes a empu kaki, lit. «senhor do pé», que se aplica ao dedo grande do pé.

39 Lit. «nariz da mão», composto que os modernos dicionários não registam, chamando -se em geral ao polegar ibu tangan, «madre da mão» ou empu tangan, «senhor da mão».

4० Tunjuk é o verbo que significa «indicar»; o seu uso como substantivo é dialectal, próprio de Menancabo (Samatra); de resto diz-se telunjuk, forma infixada da mesma raiz.

${ }^{41}$ Jari significa «dedo» em geral; o terceiro dedo é geralmente designado por jari tengah, «dedo do meio».

${ }^{42}$ Em malaio, como em muitas outras línguas asiáticas, existem termos diferentes para designar: $\mathrm{I}^{\circ}$ : a «planta de arroz» e o «arroz com casca» (bate em português de Goa, bhat em concanim, néli em português de Timor, hare em tétum) ditos em malaio padi; $2^{\circ}$ : o «arroz descascado» (tandu ou tandull em concanim, fos em tétum, em chinês 米, lido mâi em cantonense e mi em mandarim), dito em malaio beras; $3^{\circ}: 0$ «arroz cozido», pronto a comer (xit em concanim, êtu em tétum, em chinês 飯, lido fán tanto em cantonense como em mandarim), dito nasi em malaio. Segundo Bausani a tanscrição bugax (beras em malaio corrente) corresponde à pronuncia de Sulu e das Bissaias (Filipinas). 


\begin{tabular}{llllll}
\hline 70 & $\begin{array}{l}\text { Al cocho } \\
\text { in Malucho } \\
\text { et in Brunei) }\end{array}$ & $\begin{array}{l}\text { coco (em Maluco } \\
\text { e Brunei) }\end{array}$ & biazzau & piasau \\
\hline 7 I & {$[$ cocho] in Luzon } & coco (em Lução) & nior & nyiur & 44 \\
\hline 72 & {$[$ cocho] in Java } & $\begin{array}{l}\text { coco (em Java } \\
\text { Maggiore }\end{array}$ & calambil & krambil & 45 \\
\hline 73 & Al figuo & $\begin{array}{l}\text { figo [da Índia], } \\
\text { banana }\end{array}$ & pizam & pisang & 46 \\
\hline 74 & A le canne dolce & cana-doce & tubu & tebu & 47 \\
\hline 75 & A le batate & batatas & gumbili & kembili & \\
\hline
\end{tabular}

43 Piasau é forma usada em malaio de Brunei, correspondente à forma piasaw em murut ou tomugon (língua falada no norte de Sabah, na parte de Bornéu pertencente à Malásia); em malaio corrente a forma vernácula é nyiur, mas a mais usual é o empréstimo sanscrítico kelapa (do sânscrito kalpa [vṛkșa] nome da mítica árvore de que se pode extrair tudo o que se deseja, aludindo à multifária utilidade do coqueiro).

44 Note-se que a expedição não tocou Lução; mas à época os portugueses (talvez por confusão entre luçon e dusun, nome de uma etnia do norte de Bornéu) designavam genericamente por luções todos os povos do norte de Bornéu e das Filipinas. Em tagalo, a principal língua de Lução, a forma é niyóg. Formas semelhantes ocorrem em numerosas outras línguas austronésias: vide D. T. Tryon (I995 v. 3, nº o8.820, p. 248-249). Assim também nas línguas de Timor: $n u$ em tétum, nó em galoli, noa em quêmac, nunu (se bem me recordo!) em mambae e em baiqueno, etc. A forma recolhida em Malaca pelo(s) compilador(es) do Glossário Chinês-Malaio, 牛兒niu êrh, corresponde a nyur. Coco foi o nome dado pelos marinheiros de Vasco da Gama quando pela primeira vez o viram em Moçambique, porque o coco descascado, com as três cavidades características, lhes pareceu uma «côca» de meter medo aos meninos que se não comportam bem.

45 Por «Java Maior» entendia Marco Polo a Java propriamente dita, correspondendo a sua «Java Menor» a Samatra, conquanto seja muito mais vasta do que Java; a expedição não tocou nem uma nem outra, mas Pigafetta refer-se-lhes com certo detalhe, graças aos seus informadores locais. Em jau ou javanês krambil usa-se em ngoko (linguagem informal a que se fala a iguais ou inferiores), ao passo que em kråmå (linguagem de cortesia em que se fala aos superiores) se usa klåpå, correspondente ao malaio kelapa. Em javanês antigo existia

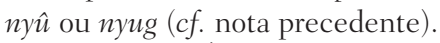

${ }^{6}$ Figo-da-Índia, figo-de-jardim, figo-de-horta, são antigos nomes da «banana», usados ainda hoje em Damão e em Goa; banana, já registado por Garcia de Orta como termo da Guiné, deriva do manjaco be-nana, «bananeira» (ao passo que «banana» se diz pe-nana e «bananas» me-nana) e acabou por suplantar figo-da-Índia em quase toda a parte.

47 Não se trata certamente da batata-doce [Ipomæa batatas, (1.) Lam, da família das Convolvuláceas] que só mais tarde foi trazida do Novo Mundo pelos espanhóis, difundindo-se a partir das Filipinas, nem muito menos da batata-semilha (Solanum tuberosum, L., 


\begin{tabular}{llllll}
\hline 76 & Al melone & melão & antimon & entimun & ubi \\
\hline 77 & $\begin{array}{l}\text { A le radice } \\
\text { como ravi }\end{array}$ & raízes como nabos & ubi & 49 \\
\hline 78 & A le ciachare & jaca (?) & mandicai, sicui & $\begin{array}{l}\text { mendikai, [buah] } \\
\text { sekui }\end{array}$ & $5^{8}$ \\
\hline 79 & A le angurie & melancias & labu & labu & $5^{\text {I }}$ \\
\hline 80 & A la vacqua & vaca & lambu & lembu \\
\hline 8 I & Al porco & porco & babi & babi \\
\hline 82 & Al bophalo & búfalo & carbau & kerbau \\
\hline
\end{tabular}

da família das Solanáceas) cuja difusão é ainda mais tardia, mas de um tubérculo usado localmente na alimentação, o Plectranthus rotundifolius, (Poir.) Spreng, da família das Labiadas, outrora classificado como Coleus tuberosus (Blume) Benth., que Pigafetta assimilou à batata-doce das Antilhas. Parece ser esta a mais antiga ocorrência em italiano do termo batata, sem dúvida de origem taíno, embora em latim esteja atestado desde 1516 , na pena de Pedro Mártir de Angléria, em castelhano desde 1519 e em português desde I554. Manillo Cortelazzo e Paolo Zolli (1979) só o registam em 1550-59 na obra de Ramúsio.

$4^{8}$ Entimun, hentimun, ketimun ou mentimun, designam o «pepino», em italiano cetriolo (Cucumis sativus, L., das Cucurbitáceas) e não o melão (Cucumis melo, L.).

49 Ubi é o nome genérico de vários tubérculos comestíveis; na época devia aplicar-se sobretudo aos inhames (Dioscorea spp., L., das Dioscoreáceas), mas, sobretudo com especificações, veio a aplicar-se a plantas botanicamente muito diferentes: ubi jalar veio a designar a «batata-doce», ubi kayu (lit. «inhame de pau») a «mandioca» (Manihot esculenta, Crantz, das Euforbiáceas), etc.

$5^{\circ} \mathrm{O}$ termo italiano não consta dos dicionários, mas é utilizado em I5ı por Ludovico di Varthema, para descrever um dos «frutos de Calecut» que descreve pormenorizadamente e é indubitavelmente a jaca [Artocarpus integer (Thunb.) Merr, ou A. integrifolia, L. fil., da família das Moráceas]; Pigafetta alude-lhe noutro passo onde o diz «muito refrescante», o que corresponde mais à pateca ou melancia [Citrullus lanatus (Thunb.) Matsum, ou C. vulgaris, Schrader, outrora classificado como Cucumis citrullus, (L.) Ser., das Cucurbitáceas], que é de facto o fruto designado em malaio corrente por mendikai e no dialeto de Brunei por buah sekui. Provavelmente Pigafetta leu o Itinerário de Varthema e identificou apressadamente a melancia com que topou com fruto descrito pelo seu predecessor, que com ela apenas tem em comum a grande dimensão.

${ }^{5}$ Anguria é um termo regional, usado para designar o que noutras partes se chama cocomero, que é a pateca ou melancia (vide nota precedente); Bausani pensa que aqui designa o pepino, e traduz em inglês por cucumber. No entanto os dicionários de malaio atribuem a labu os significados de «espécie de abóbora» [Cucurbita moschata, (Duchesne) Duchesne ex Poir] e de «cabaça» [Lagenaria siceraria, (Molina) Standl., da mesma família]. O Glossário Chinês-Malaio dá 的悶ti mên, i. e. timun para «pepino» $\mathrm{e}$ 悶的格 mên ti ko, i.e. mendikai para «melancia», o que é correto; mas 不的pu ti, i. e., beték (do árabe e persa 


\begin{tabular}{|c|c|c|c|c|c|}
\hline 83 & A la pecora & ovelha & biri & biri-biri & \\
\hline 84 & A la capra & cabra & cambin & kambing & \\
\hline 85 & Al galo & galo & sambunghan & [ayam] sabungan & 52 \\
\hline 86 & A la galina & galinha & aiambatina & ayam betina & 53 \\
\hline 87 & Al cappone & capão & gubili & [ayam] kebiri & 54 \\
\hline 88 & $\mathrm{Al}$ ovo & OVo & talor & telur & \\
\hline 89 & Al occato & ganso & itich & itik & 55 \\
\hline 90 & $\mathrm{Al}$ ocqua & gansa & ansa & angsa $(\mathrm{S})$ & $5^{6}$ \\
\hline $9 \mathrm{I}$ & Al ucello & ave & bolon & burung & \\
\hline 92 & Al elephante & elefante & gagia & gajah $(\mathrm{S})$ & \\
\hline 93 & Al cavalo & cavalo & cuda & kuda (S) & \\
\hline 94 & Al leone & leão & hurimau & harimau & 57 \\
\hline 95 & $\mathrm{Al}$ cervo & cervo, veado & roza & rusa & \\
\hline 96 & Al cane & cão, perro & cuiu & kuyuk & $5^{8}$ \\
\hline 97 & Alle hape & abelhas & haermadu & air madu $(\mathrm{S})$ & 59 \\
\hline 98 & $\mathrm{Al}$ melle & mel & gula & gula & 60 \\
\hline 99 & A la cera & cera & lelin & lilin & \\
\hline
\end{tabular}

bițtikh, étimo do português pateca) para «melão doce» o que mostra a mesma tendência para confundir as diversas cucurbitáceas.

52 Sabungan significa propriamente «animal de combate» (da $\sqrt{ }$ sabung, «colidir, combater»); mas em todo o Arquipélago, onde as lutas de galos são assaz populares, o animal de combate por excelência é o galo.

53 Não havendo em malaio género gramatical, todos os nomes de animais são epicenos, ajuntando-se-lhes, quando se quer especificar o sexo, jantan, «macho» ou betina, «fêmea».

54 Ayam significa «galo / galinha» e kebiri, «capado».

55 Itik não designa o ganso, mas o adem, parreco ou pato marreco.

$5^{6}$ Angsa, do sânscrito hamisa ou hãsa, «ganso silvestre» e, poeticamente, «cisne, animal alado, ave fabulosa», tanto designa o ganso como o cisne.

57 Harimau não designa o leão mas o reimão ou tigre; mas a confusão entre os dois animais é comum nas regiões em que não há leões, como sucede em persa da Índia onde šêr, «leão», é por vezes utilizado para o tigre. O nome do leão é em malaio singa e na maioria das línguas da Índia singh, do sânscrito simha.

$5^{8}$ Kuyuk é uma interjeição para chamar os cães, usada em Brunei como nome do próprio animal; o termo corrente é anjing.

59 Air madu não significa «abelha» mas «mel» (lit. «água de mel»). A abelha é lebah (ou lebah madu, «abelha de mel», para a distinguir da vespa).

60 Gula não significa «mel» (que se diz madu, do sânscrito madhu), mas «açúcar» e com especificativos como mérah, «vermelho» também «jagra, açúcar de palma» (dito, consoantes as regiões, gula mérah, «açúcar vermelho», gula Jawa ou gula Melaka). 


\begin{tabular}{|c|c|c|c|c|c|}
\hline 100 & A la candella & vela, círio & dian & dian & \\
\hline $\mathrm{IOI}$ & Al suo stopino & o seu pavio & sumbudian & sumbu dian & \\
\hline 102 & Al fuoco & fogo & appi & api & \\
\hline 103 & $\mathrm{Al}$ fumo & fumo & asap & asap & \\
\hline 104 & A le cenere & cinzas & abu & abu & \\
\hline 105 & Al cucinato & cozinhado & azap & asap & 61 \\
\hline 106 & $\mathrm{Al}$ molto cucinato & muito cozinhado & lambech & lémbak & 62 \\
\hline 107 & $\mathrm{Al}$ hacqua & água & tubi & tubig & 63 \\
\hline 108 & $\mathrm{Al}$ oro & ouro & amax & emas & \\
\hline I09 & $\mathrm{Al}$ argento & prata & pirac & pérak & \\
\hline IIO & A la pietra preciosa & pedra preciosa & premata & permata & \\
\hline III & A la perla & pérola & mutiara & mutiara $(\mathrm{S})$ & \\
\hline II 2 & $\mathrm{Al}$ argento vivo & azougue, mercúrio & raza & $\operatorname{raksa}(\mathrm{S})$ & \\
\hline II3 & Al metalo & metal & tumbaga & tembaga $(\mathrm{S})$ & 64 \\
\hline II 4 & Al fero & ferro & baci & besi & \\
\hline II5 & Al piombo & chumbo & tima & timah & 65 \\
\hline II6 & A le sue borchie & tachas, brochas & agun & agung, gung, gong & 66 \\
\hline II 7 & A lo cenaprio & $\begin{array}{l}\text { cinábrio, } \\
\text { vermelhão }\end{array}$ & galuga sadalinghan & $\begin{array}{l}\text { geluga, } \\
\text { sedelinggam }\end{array}$ & 67 \\
\hline II 8 & $\mathrm{Al}$ argento & prata & soliman danas & $?$ & 68 \\
\hline
\end{tabular}

6r Como vimos acima ( $\mathrm{n}^{\circ}$ Iо3) este termo significa «fumo»; pode significar «cozinhado» no sentido de «fumado, defumado», como em daging asap, «carne fumada».

62 Há aqui uma distorção semântica, pois lémbak significa «transbordar».

63 Tubig significa de facto «água», mas em tagalo, bissaia e outras línguas das Filipinas e de Celebes; em malaio é air, que o Glossário Chinês-Malaio transcreve por 亞兒ya (cant. a) i êrh.

${ }^{6}$ Tembaga não significa metal in genere, mas «cobre» ou «liga de cobre» (tembaga kuning, lit. «cobre amarelo» é o arame ou latão, t. mérah, «cobre vermelho», o cobre propriamente dito, t.putih, «cobre branco», o peltre, etc.).

${ }_{5}$ Timah não significa «chumbo», mas «estanho»; chumbo diz-se correntemente timah hitam, lit. «estanho negro»; em Java usa-se timbel.

${ }^{66}$ Este termo é o étimo do português gongo, e significa o mesmo e não «tacha».

${ }_{67}$ Geluga é termo regional, usado em Java; sedelinggam é de uso mais geral, mas designa mais propriamente o mínio ou zarcão (óxido de chumbo, $\mathrm{Pb}_{3} \mathrm{O}_{4}$ ), que tem as mesmas propriedades corantes do cinábrio (sulfureto de mercúrio, $\mathrm{S} \mathrm{Hg}$ ), com que é bastas vezes confundido.

68 Inidentificável; o termo para «prata» vai acima, no ${ }^{\circ}$ og. Suliman ou Sulaiman é Salomão; dana (S) significa «esmola, montepio, fundo monetário»; o seu étimo sânscrito sig- 


\begin{tabular}{|c|c|c|c|c|c|}
\hline II9 & Al panno de seta & pano de seda & cain sutra & kain sutera (S) & \\
\hline 120 & Al panno rosso & pano vermelho & cain mira & kain mérah & \\
\hline I2I & $\mathrm{Al}$ panno negro & pano negro & cain ytam & kain hitam & \\
\hline $\mathrm{I} 22$ & Al panno biancho & pano branco & cain pute & kain putih & \\
\hline 123 & $\mathrm{Al}$ panno verde & pano verde & cain igao & kain hijau & \\
\hline $\mathrm{I} 24$ & Al panno giallo & pano amarelo & cain cunin & kain kuning & \\
\hline 125 & Al bonnet & boné, cofió & cophia & kopiah (A) & 69 \\
\hline $\mathrm{I} 26$ & $\mathrm{Al}$ cortello & faca, cutelo & pixao & pisau & \\
\hline 127 & A la forfice & tesoura & guntin & gunting & \\
\hline $\mathrm{I} 28$ & Al spequio & espelho & chielamin & cermin & \\
\hline 129 & Al petine & pente & sissir & sisir & \\
\hline 130 & Al cristalino & $\begin{array}{l}\text { conta de cristal ou } \\
\text { de vidro }\end{array}$ & manich & manik $(S)$ & \\
\hline I3I & Al sonaglio & guiso, campaínha & girin girin & giring-giring & \\
\hline 132 & $\mathrm{Al}$ annello & anel & $\sin \sin$ & cincin & \\
\hline $\mathrm{I} 33$ & aa li garopholi & $\begin{array}{l}\text { cravos girofos, } \\
\text { cravinho }\end{array}$ & ghianche & cengkéh & \\
\hline $\mathrm{I} 34$ & a la cannela & canela & caiumanis & kayu manis & 70 \\
\hline 135 & al pevere & pimenta & lada & lada & \\
\hline 136 & al pevere longo & pimenta-longa & sabi & cabé, cabai & 71 \\
\hline
\end{tabular}

nifica «riqueza». Quereria o informador de Pigafetta dizer que a prata era a riqueza de Salomão?

${ }^{69}$ Por intermédio do árabe (kûfiyya ou kâfiyya) e do italiano (cuffia), o termo, da mesma origem do português coifa, remonta em última análise ao baixo-latim cuffiam, por seu turno, ao que parece de origem germânica; a forma cofió deriva do mesmo étimo por intermédio do árabe e de qualquer língua da Guiné. Não existindo em malaio o fonema $f$, é, nos empréstimos árabes, normalmente realizado p. O Glossário Chinês-Malaio dá para «pequeno chapéu» o mesmo termo, numa forma mais próxima do árabe: 孤非亞 $k u$-fei-ya.

$7^{\circ}$ Lit. «pau doce».

${ }^{71}$ Hoje o termo cabé ou cabai usa-se sobretudo para designar o pimentão (Capsicum annumm, L. das Solanáceas), oriundo do Novo Mundo e portanto ainda desconhecido na Insulíndia nesta época, pelo que se engana Bausani ao identificar com ele o vocábulo dado por Pigafetta. No mesmo erro incorre Theodore G. Th. Pigeaud nas suas anotações ao Nâgarakertâgama (Java in the I4th Century - A study in Cultural History, 5 vols, KITLV, Leida, I960-63). Outrora, porém, e por vezes ainda hoje, servia para designar a pimenta-longa do Sueste Asiático (Piper retrofactum, Vahl., das Piperáceas), e é essa sem dúvida a que está em causa aqui. A pimenta-longa do NE da Índia, conhecida em Brunei e na Europa talvez já desde o século v a. C. (Piper longum, L.), é uma espécie distinta. 


\begin{tabular}{|c|c|c|c|c|c|}
\hline I37 & a la noce moscada & noz-moscada & buapala gosoga & $\begin{array}{l}\text { buah pala }(\mathrm{S}) \text {, } \\
\text { gosora }\end{array}$ & 72 \\
\hline 138 & Al filo de ramo & fio de arame & cauot & kawat & 73 \\
\hline I39 & $\mathrm{Al}$ piato & prato & pinghan & pinggan & \\
\hline 140 & A la pigniata & pote, panela & priu & periuk & \\
\hline I4I & A la scutela & malga, tigela & manchu & mangkuk & \\
\hline 142 & $\mathrm{Al}$ piato di legnio & prato de pau & dulan & dulang & \\
\hline I43 & A la conqua & alguidar, concha & calunpan & kelompang & 74 \\
\hline I44 & A le sue mesure & as suas medidas & socat & sukat & 75 \\
\hline 145 & A la terra & terra & buchit & bukit & 76 \\
\hline 146 & A la terra ferma & terra-firme & buchit tana & bukit tanah & 77 \\
\hline I47 & A la montagna & montanha & gunun & gunung & \\
\hline 148 & A la pietra & pedra & batu & batu & \\
\hline I49 & Al ysola & ilha & pulau & pulau & \\
\hline 150 & A un capo de terra & cabo, promontório & taniun buchit & tanjung, bukit & \\
\hline I5I & Al fiume & rio & songhai & sungai & \\
\hline 152 & $\begin{array}{l}\text { Come se chiama } \\
\text { questo? }\end{array}$ & $\begin{array}{l}\text { como se chama } \\
\text { isto }\end{array}$ & apenamaito? & apa nama itu? & $7^{8}$ \\
\hline 153 & Al oleo de cocho & óleo de coco & mignach & minyak & 79 \\
\hline I54 & $\mathrm{Al}$ oleo de giongioli & óleo de gergelim & lana lingha & minyak, lenga & 80 \\
\hline
\end{tabular}

72 O elemento pala parece vir do sânscrito phala, «fruto», usado por antonomásia; gosora é, segundo Bausani que se louva em Gonda, termo de Ternate e Halmaheira.

73 Hoje, tal como o português arame, usa-se também para o fio de ferro ou de outro metal.

74 Kelompang não é exatamente um «alguidar» nem uma «concha» (dois sentidos possíveis do italiano conca), mas uma casca de ovo vazia, que com ambos compartilha a caráter côncavo.

75 No norte da Malásia e em malaio literário sukat significa genericamente «medida», seja de capacidade, seja de comprimento ou de outra dimensão; mas mais geralmente designa uma medida para secos equivalente a um alqueire ou 12,6 litros, que se subdivide em 4 gantas (gantang).

${ }^{6}$ Bukit não significa «terra», mas «monte»; «terra» diz-se tanah.

77 Bukit tanah significa «monte de terra»; «terra-firme», por oposição a água, diz-se darat; por oposição a ilha, diz-se benua, «continente».

$7^{8}$ De verbo ad verbum: «qual nome isto».

79 Minyak significa «óleo» em geral; para se especificar que é de coco há que dizer minyak kelapa ou m. nyiur.

80 Minyak é o termo malaio, lenga, o javanês; lana ocorre em tagalo, palawan e outras línguas da região (Tryon I995, 05.790). 


\begin{tabular}{|c|c|c|c|c|c|}
\hline 155 & $\mathrm{Al}$ sale & sal & garan sira & garam, sira & 81 \\
\hline 156 & $\begin{array}{l}\text { Al muschio } \\
\text { e al suo animale }\end{array}$ & $\begin{array}{l}\text { o almíscar e o } \\
\text { animal que o dá }\end{array}$ & castori & kesturi (S) & 82 \\
\hline I 57 & $\begin{array}{l}\text { Al legno che man- } \\
\text { giano li castori }\end{array}$ & $\begin{array}{l}\text { o pau que comem } \\
\text { os castores }\end{array}$ & comaru & $?$ & 83 \\
\hline 158 & A la sansuga & sanguessuga & linta & lintah & \\
\hline 159 & $\mathrm{Al}$ gibeto & almiscareiro & jabat & jebat (A) & 84 \\
\hline 160 & $\begin{array}{l}\text { Al gato che } \\
\text { fa lo gibeto }\end{array}$ & gato-de-algália & muzan & musang & 85 \\
\hline I6I & $\mathrm{Al}$ reobarbaro & ruibarbo & calama & kelembak & 86 \\
\hline
\end{tabular}

8r Sira é o nome do sal em diversas línguas do Arquipélago, como o achém e o bata do norte de Samatra (Tryon I995, 05.80I) e, segundo Bausani, também em Celebes, Ceirão, etc. Wilkinson registra sirah, «sal» em malaio de Brunei.

${ }_{2}$ Do sânscrito kastûrî, «almíscar», que através do malaiala deu em português casturi, apenas utilizado no sentido figurado de «ósculo da paz» que lhe dão os cristãos siro-malabares. Embora o mesmo odor esteja presente em outros mamíferos e até em aves e em répteis, o animal que dá o almíscar que aparece no comércio é o almiscareiro, cabra-almiscarada ou cervo-almiscarado (Moschus moschiferus, L., da família dos Viverrídeos), que o segrega das suas glândulas genitais masculinas. O animal é encontradiço na Mongólia, Sibéria, Manchúria e Coreia, mas não no Sueste Asiático, onde existem, contudo, espécies aparentadas, como a Viverra zibetha, L., que dá um perfume menos apreciado.

$8_{3}$ Não é possível identificar este termo, tanto mais que a sua equivalência em italiano é assaz vaga; Bausani aventa várias hipóteses, nenhuma delas satisfatória. Aparentemente Pigafetta deixa-se levar pela paronímia, associando o almíscar (kesturi em malaio), produzido por animais da família dos Viverrídeos, que são ruminantes, ao castor (de que existem duas espécies, o Castor fiber, L., e o Castor canadensis Kuhl, da família dos Castorídeos) que é um roedor.

${ }^{8} 4$ Cf. supra o vocábulo nº 156 . Jebat provém do árabe zabâd, que está na origem do italiano zibetto, de onde o francês civette, o inglês civet, etc.

${ }_{5}$ Musang é em várias regiões do Mundo Malaio o nome genérico dos Viverrídeos; aplica-se sobretudo a animais do género Paradoxurus (lit. «de extraordinária cauda»), de que a maior parte produz pouco ou nenhum aroma de almíscar, como sucede ao animal existente em Timor e aí designado por laco (Paradoxurus hermaphroditus musanga, Raff.). Por analogia musang usa-se hoje para traduzir na literatura o nome da «raposa», inexistente no Arquipélago, mas que possui também uma imponente cauda. O verdadeiro gato-de-algália ou civeta-africana (Civettictis civetta, Schreber, da mesma família), conhecido por lagaia em S. Tomé e Príncipe, é uma espécie africana, inexistente na Ásia, que produz a algália, perfume semelhante ao almíscar.

86 Kelembak não designa o ruibarbo (Rheum rhebarbarum, L., da família das Poligonáceas) mas a águila, calambac calambuco, linaloés ou lenho-aloés [Aquilaria malaccensis, 


\begin{tabular}{|c|c|c|c|c|}
\hline I62 Al demonio & demónio & saytan & sétan (A) & \\
\hline I63 $\mathrm{Al}$ mondo & mundo & bumi & bumi (S) & 87 \\
\hline I64 $\mathrm{Al}$ fromento & trigo, frumento & gandun & gandum $(\mathrm{P})$ & 88 \\
\hline I65 Al dormire & dormir & tidor & tidur & \\
\hline I66 A le store & esteiras & tical & tikar & \\
\hline I67 $\mathrm{Al}$ cussino & coxim, almofada & bantal & bantal & \\
\hline I68 $\mathrm{Al}$ dolore & dor & sachet & sakit & \\
\hline I69 A la sanitate & saúde & bay & baik & 89 \\
\hline I70 Alla sedola & $?$ & cupia & kupiah (A?) & 90 \\
\hline I7I Al sparaventolo & abano, leque & chipas & kipas & \\
\hline I72 A li sui panni & os seus panos & chebun & kebun & 91 \\
\hline I73 A le camise & camisas & baiu & baju $(\mathrm{P})$ & 92 \\
\hline I74 A le sua case & as suas caixas & pati alam & peti alang (?) & 93 \\
\hline
\end{tabular}

Lam. e espécies vizinhas como a A.agallocha (Lour.) Roxb., da família das Timeleáceas], em que se forma uma concreção, de origem patológica [devida a infeção pelo Phaeoacremonium parasiticum (Ajello, Georg \& C.J.K. Wang) W. Gams, Crous \& M.J. Wingf.], que é altamente aromática; conhecida na Europa desde a Antiguidade é mencionada já como

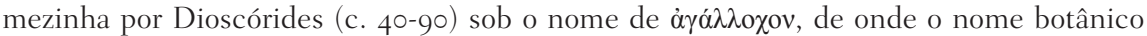
dado pelo Pe Loureiro a uma das espécies que identificou na Cochinchina. É provável que o aloés mencionado como perfume na Bíblia (Num 24, 6; Prov 7, i7; Cant 4,I4, etc.) seja identificável com uma destas espécies, pois o vulgar aloé ou azebre [Aloe vera, (L.) Burm. f. da família das Liliáceas], relativamente comum no litoral português e na zona mediterrânica em geral, não é particularmente aromático.

${ }^{87}$ Bumi (do sânscrito bhûmî, «Terra») é o «mundo» no sentido restrito de «Terra», em que, na forma布迷 pu-mi, consta já do Glossário chinês-malaio acima citado; em sentido mais geral de «natureza, criação, universo» é alam (do árabe 'alam) ou, no sentido de «mundo material», oposto ao céu ou à eternidade, dunia (do árabe dunyâ).

${ }^{88} \mathrm{O}$ termo usa-se hoje bastas vezes no sentido genérico de «grão, cereal»; para o trigo em particular usa-se hoje as mais das vezes o empréstimo português terigu; o Glossário Chinês-Malaio dá 昆冬 k'un-tung, i. e., gandum, como equivalente a «farinha».

89 Baik significa «bom, bem» em qualquer sentido; para «são, de boa saúde» usa-se séhat.

90 Trata-se aparentemente de uma repetição do vocábulo $\mathrm{n}^{0}$ 125; mas o termo italiano não se encontra nos dicionários; seggiola, «assento, cadeira» não faz sentido aqui.

${ }^{11}$ Kebun existe, mas significa «jardim, horta, plantação».

${ }_{92}$ Baju (termo que passou ao português), do persa bâz $\hat{u}$, «braço» designa genericamente qualquer vestimenta com mangas.

93 Como peti significa «caixa» é necessário restituir o italiano cassa em vez de casa; peti alang será uma «caixa com divisórias», pois alang significa «barra transversal, tabique, divisória». Bausani, louvando-se em Gonda, interpreta aluang, como «arca»; o termo não é malaio mas menancabo (Samatra ocidental). 


\begin{tabular}{|c|c|c|c|c|}
\hline I75 $\mathrm{Al}$ anno & ano & taun & tahun & \\
\hline I76 Al mese & mês & bullan & bulan & 94 \\
\hline I77 $\mathrm{Al} \mathrm{di}$ & dia & alli & hari & \\
\hline I78 A la nocte & noite & mallan & malam & \\
\hline I79 $\mathrm{Al}$ tarde & tarde & malamari & malam hari & \\
\hline I80 Al mezodi & meio-dia & tamhahari & tengah hari & \\
\hline I8I A la matina & manhã & patan patan & petang & 95 \\
\hline I82 $\mathrm{Al}$ solle & sol & mata hari & matahari & 96 \\
\hline I83 A la luna & lua & bulan & bulan & \\
\hline I84 A la mezzaluna & meia-lua & tanampat bulan & tengah empat bulan & 97 \\
\hline I85 A le stelle & estrelas & bintan & bintang & \\
\hline I86 Al ciello & céu & languin & langit & \\
\hline I87 $\mathrm{Al}$ trono & trovão & gunthur & guntur & \\
\hline I88 Al merchadante & mercador & saudagar & saudagar $(\mathrm{P})$ & \\
\hline I89 A le citade & cidades & naghiri & negeri $(\mathrm{S})$ & 98 \\
\hline I90 Al castello & $\begin{array}{l}\text { castelo, lugar } \\
\text { fortificado }\end{array}$ & kuta & $\operatorname{kota}(S)$ & 99 \\
\hline I9I A la casa & casa & ruma & rumah & \\
\hline I92 Al sedere & $\begin{array}{l}\text { sentar-se, estar } \\
\text { sentado }\end{array}$ & duodo & duduk & \\
\hline I93 Sedeti gentilhomo & $\begin{array}{l}\text { senta-te, gentil- } \\
\text {-homem! }\end{array}$ & duodo orancaia & duduk orang kaya & 100 \\
\hline
\end{tabular}

94 Lit. «lua».

95 Petang significa o inverso: «tarde, entardecer»; a forma redobrada petang petang significa «fim de tarde, anoitecer».

$9^{6}$ Lit.: «olho (mata) do dia (hari)».

97 Bulan significa «lua»; setengah empat significa «metade [para as] quatro, i. e., três e meia»; a expressão equivale portanto a «lua a três quartos», i. e. «quarto minguante», o que de facto corresponde visualmente a «meia-lua».

$9^{8}$ O étimo sanscrítico (nagarî, forma feminina derivada de nagara, «cidade») significa «cidade, capital», mas em malaio o termo usa-se hoje principalmente no sentido de «país, estado, território dependente de uma capital».

99 Do sânscrito, por seu turno de origem dravídica, koțta, «fortificação, lugar fortificado», sentido em que, na forma谷達 ku-ta, consta do Glossário chinês-malaio do século xv e que se mantém na Malásia, em Menancabo, em Timor, etc.; mas na Indonésia em geral o vocábulo usa-se hoje no sentido genérico de «cidade», para que na Malásia se prefere o termo persa bandar, «porto», étimo do português bandel.

100 Orang kaya, lit. «homem rico» significa na linguagem clássica «rico-homem, nobre, senhor malaio, orancaia» independentemente da riqueza efetiva que possua. 


\begin{tabular}{|c|c|c|c|c|c|}
\hline 194 & $\begin{array}{l}\text { Sedeti homo } \\
\text { da benne }\end{array}$ & $\begin{array}{l}\text { senta-te, homem } \\
\text { de bem! }\end{array}$ & $\begin{array}{l}\text { duodo horambai et } \\
\text { anan }\end{array}$ & $\begin{array}{l}\text { duduk, orang baik, } \\
\text { ke tanah (?) }\end{array}$ & 101 \\
\hline 195 & Signor & senhor & tuan & tuan & \\
\hline 196 & $\mathrm{Al}$ puto & $\begin{array}{l}\text { puto, menino, } \\
\text { criança }\end{array}$ & cana cana & kanak-kanak & \\
\hline I97 & Al uno suo alievo & aluno seu & lascar & lasykar $(\mathrm{P})$ & 102 \\
\hline 198 & Al schiavo & escravo & alipin & alipin & 103 \\
\hline 199 & $\mathrm{Al}$ si & $\operatorname{sim}$ & са & ia & 104 \\
\hline 200 & $\mathrm{Al}$ no & não & tida & tidak & \\
\hline 201 & Al intendere & entender & thao & tahu & \\
\hline 202 & $\mathrm{Al}$ non intendere & não entender & tida taho & tidak tahu & \\
\hline 203 & Non mi gardare & não me olhes! & tida liat & tidak lihat & 105 \\
\hline 204 & guardame & olha-me & liat & lihat & \\
\hline 205 & $\begin{array}{l}\text { A essere una me- } \\
\text { desima cosa }\end{array}$ & ser a mesma coisa & $\begin{array}{l}\text { casicasi, siama } \\
\text { siama }\end{array}$ & $\begin{array}{l}\text { kasih kasih, sama } \\
\text { sama }(\mathrm{S})\end{array}$ & 106 \\
\hline 206 & $\mathrm{Al}$ mazare & matar & mati & mati & 107 \\
\hline 207 & $\mathrm{Al}$ mangiare & comer & macan & makan & \\
\hline 208 & Al iuchiaro & colher, cocharra & sandoch & séndok & \\
\hline 209 & A la magalda & meretriz & sondal & sundal & \\
\hline 210 & Grande & grande & bassal & besar & \\
\hline
\end{tabular}

ır Duduk orang baik significa «senta-te, bom homem» (orang, em rigor significa «pessoa», independentemente do sexo); seguimos a Bausani, que interpreta et anan como correspondente a ke tanah, «no chão».

${ }^{102}$ Laškâr em persa (e daí em malaio e outras línguas) significa «soldado», de onde o português lascar, «soldado nativo»; lascarim provém do adjetivo derivado laškârî, «militar»; para «aluno» usa-se o termo árabe murid.

${ }^{103}$ Alipin é o termo tagalo para «escravo»; o malaio possui diversos termos: hamba, sahaya (S), abdi (A), etc.: vide Thomaz (1994).

${ }_{104} \mathrm{Ca}$ deve ser erro de copista por $e a$, transcrição aproximada de $i a$, «ele, ela», que se usa por vezes no sentido de «isso! sim!»; tal como em português, usa-se pouco, sendo mais normal repetir o verbo: Bapak ada? Ada!, «o pai está? Está!».

105 Na realidade tidak lihat significa «não vejo, não vês, etc.», pois tidak é uma negativa simples, meramente assertiva, que serve para negar um ato, um estado ou uma qualidade, sendo jangan a negativa proibitiva ou intencional, ao passo que lihat é «ver» e não «olhar», que se diz pandang.

106 Sama significa efetivamente «mesmo, idêntico» e sama-sama, «juntamente, igualmente» ou «iguais entre si»; mas kasih significa «amar» ou, coloquialmente, «dar».

${ }^{107}$ Mati não significa «matar», mas «morrer»; «matar» diz-se bunuh, ou, quando muito, mematikan, «fazer morrer» (forma causativa de mati). 


\begin{tabular}{|c|c|c|c|c|c|}
\hline $2 \mathrm{II}$ & Longo & longo, comprido & pangian & panjang & \\
\hline 212 & Picolo & pequeno & chechil & kecil & \\
\hline 213 & Corto & curto & pandach & péndék & \\
\hline 214 & Al havere & ter, haver & ada & ada & 108 \\
\hline 215 & $\mathrm{Al}$ no havere & não ter, não haver & tida hada & tidak ada & \\
\hline 216 & Signior ascolta! & senhor, escuta! & tuan diam & tuan diam & 109 \\
\hline 217 & $\begin{array}{l}\text { Dove viene } \\
\text { il ionco? }\end{array}$ & $\begin{array}{l}\text { de onde vem o } \\
\text { junco? }\end{array}$ & dimana ajun? & dimana (a)jung? & 110 \\
\hline 218 & $\begin{array}{l}\text { A la guquia } \\
\text { da cusire }\end{array}$ & agulha de coser & jalun & jarum & \\
\hline 219 & $\mathrm{Al}$ cusire & coser & banan & benang & 111 \\
\hline 220 & Al filo da cusire & fio de coser & pintal benan & pintal benang & 112 \\
\hline $22 \mathrm{I}$ & $\begin{array}{l}\text { A la scufia del } \\
\text { capo }\end{array}$ & $\begin{array}{l}\text { barrete, boné da } \\
\text { cabeça }\end{array}$ & dastar capala & $\begin{array}{l}\text { destar (P) kepala } \\
(\mathrm{S})\end{array}$ & 113 \\
\hline 222 & Al re & rei & raia & raja $(\mathrm{S})$ & \\
\hline 223 & A la reyna & rainha & putli & puteri $(\mathrm{S})$ & 114 \\
\hline 224 & Al legnio & $\begin{array}{l}\text { pau, madeira, } \\
\text { lenho }\end{array}$ & caiu & kayu & \\
\hline 225 & Al stentar & $?$ & caraiar & ? & \\
\hline 226 & Al salassare & sangrar, purgar & bualdala & buang darah & 115 \\
\hline 227 & $\begin{array}{l}\text { A la venna del bra- } \\
\text { cio dove se salassa }\end{array}$ & $\begin{array}{l}\text { a veia do braço } \\
\text { que se sangra }\end{array}$ & urat paratanghan & urat parah tangan & 116 \\
\hline
\end{tabular}

${ }_{108}$ Ada significa «existir», «haver (impessoal)» ou «estar (em tal ou tal lugar)»; em malaio clássico «ter, haver» diz-se ada kapada F., «ser para F., existir para F.», construção idêntica ao latim esse + dativo (ada anjing kepadaku, «est mihi canis», i. e. «tenho um cão»), e a uma construção idêntica nas línguas semíticas. No entanto, coloquialmente, usa-se muitas vezes ada transitivamente, para traduzir a noção de «ter, possuir».

109 Tuan diam significa em rigor, «senhor, cala-te» ou «senhor, fica quieto».

"1 Dimana jung (ou ajung?) significa em rigor «onde está o junco?»; «de onde vem o junco?» seria dari mana jung?

"ü Benang é a «linha de coser»; o verbo «coser»é (men)jahit.

"12 Em rigor, pintal benang é o «cordão de fio», o «fio torcido» ou «entrançado».

"13 Destar (do persa dastâr) é em rigor o turbante, que de facto se usa na cabeça (kepala).

${ }^{114}$ Puteri (do sânscrito putrî, «filha») significa em rigor «princesa».

${ }^{115}$ Buang significa «deitar fora, expelir» e darah, «sangue».

${ }^{116}$ Urat, «parte filamentosa do corpo (veia, artéria, nervo)»; parah, «grave, difícil, perigoso»; tangan, «mão», portanto «veia grave da mão»; a não ser que em vez de parah se deva ler darah, «sangue», pois urat darah significa «veia». 


\begin{tabular}{|c|c|c|c|c|c|}
\hline 228 & $\begin{array}{l}\text { Al sangue que vien } \\
\text { fora del bracio }\end{array}$ & $\begin{array}{l}\text { o sangue que sai } \\
\text { do braço }\end{array}$ & dara carnal & darah kental & 117 \\
\hline 229 & $\mathrm{Al}$ sangue buona & bom sangue & dara & darah & "118 \\
\hline 230 & $\begin{array}{l}\text { Quando stratuita- } \\
\text { no diceno }\end{array}$ & $\begin{array}{l}\text { quando espilram } \\
\text { dizem }\end{array}$ & ebarasai & ia bersin(?) & 119 \\
\hline $23 \mathrm{I}$ & $\mathrm{Al}$ pece & peixe & ycam & ikan & \\
\hline 232 & Al polpo & polvo & calabutan & kala $(\mathrm{S})$ butan & 120 \\
\hline 233 & A la carne & carne & dagin & daging & \\
\hline 234 & Al corniolo & caracol & cepot & ciput, siput & ${ }_{121}$ \\
\hline 235 & Poco & pouco & serich & sedikit & \\
\hline 236 & Mezo & meio & satanha, sapanghal & $\begin{array}{l}\text { setengah, } \\
\text { sepenggal }\end{array}$ & 122 \\
\hline 237 & $\mathrm{Al}$ fredo & frio & dinghin & dingin & \\
\hline 238 & Al caldo & cálido, quente & panas & panas & \\
\hline 239 & Longi & longe & jau & jauh & \\
\hline 240 & A la verità & verdade & benar & benar & \\
\hline $24 \mathrm{I}$ & A la bugia & $\begin{array}{l}\text { mentira, engano, } \\
\text { peta }\end{array}$ & dusta & dusta $(\mathrm{S})$ & \\
\hline 242 & $\mathrm{Al}$ robare & roubar & manchiuri & mencuri $(\mathrm{S})$ & \\
\hline 243 & A la rognia & sarna & codis & kudis & \\
\hline 244 & Piglia & toma! & na & nak (?) & 123 \\
\hline 245 & Dame & dá-me! & ambil & ambil & 124 \\
\hline 246 & Grasso & gordo & gamuch & gemuk & \\
\hline
\end{tabular}

${ }_{117}$ Lit. «sangue grosso, sangue espesso».

"18 Darah significa «sangue» em todas as acepções.

"I9 Ia bersin significa simplesmente «ele espilra» ou «ele espilrou»; o tradicional é dizer em árabe a Al hamdu l'illâhi «louvor a Deus».

120 Kala é o nome do «escorpião» (animal e constelação); segundo Bausani, kala butan é no dialeto malaio de Brunei o nome do «choco» e não do «polvo».

${ }^{121}$ Ciput ou siput é em malaio o nome do «caracol», que veio a significar «concha» em português de Timor, na forma cibo; mas o italiano corniolo, quiçá dialectal, não é registado pelos dicionários.

${ }^{122}$ Se-, forma curta de satu usada em composição, significa «um»; tengah significa metade, mas penggal significa genericamente «pedaço, bocado».

123 Nak é forma breve de hendak, «tencionar, desejar» que se usa como verbo auxiliar para formar um futuro com um ligeiro cambiante de intencionalidade (cf. inglês I will do, port. eu hei de fazer, etc.); o sentido de «tomar» está ausente do vocábulo.

${ }^{124}$ Ambil significa «toma» e não «dá-me» que se diz beri, beri kepadaku («a mim»). 


\begin{tabular}{|c|c|c|c|c|c|}
\hline 247 & Magro & magro & golos & kurus & \\
\hline 248 & Al capelo & chapéu, boné, etc. & tundun capala & tudung kepala (S) & 125 \\
\hline 249 & Quanti & quantos? & barapa & berapa & \\
\hline 250 & Una fiata & uma vez & satu chali & satu kali & \\
\hline $25 \mathrm{I}$ & Uno bracio & uma braça & dapa & depa & \\
\hline 252 & Al parlare & falar & katha & kata $(\mathrm{S})$ & 126 \\
\hline 253 & A quivi & aqui & $\operatorname{sini}$ & $\operatorname{sini}$ & \\
\hline 254 & A là & lá, ali, acolá & sana datan & sana datang & 127 \\
\hline 255 & Bon iorno & bom dia & salamalichun & $\begin{array}{l}\text { al-salamu 'alaikum } \\
\text { (A) }\end{array}$ & 128 \\
\hline 256 & $\mathrm{Al}$ rispondere & $\begin{array}{l}\text { ao responder } \\
\text { [-lhe }]\end{array}$ & alichum salam & $\begin{array}{l}\text { wa 'alaikum } \\
\text { al-salam (A) }\end{array}$ & \\
\hline 257 & $\begin{array}{l}\text { Signori, bon pro vi } \\
\text { facia! }\end{array}$ & $\begin{array}{l}\text { senhores, bom } \\
\text { proveito! }\end{array}$ & $\begin{array}{l}\text { mali horancaia } \\
\text { makan }\end{array}$ & $\begin{array}{l}\text { mari orang kaya } \\
\text { makan }\end{array}$ & 129 \\
\hline 258 & Già ho mangiato & já comi & suda macan & sudah makan & \\
\hline 259 & Homo, levati di li & $\begin{array}{l}\text { homem levanta-te } \\
\text { daí! }\end{array}$ & pandan chita oran & $\begin{array}{l}\text { pandang kita, } \\
\text { orang! }\end{array}$ & 130 \\
\hline 260 & Al disdisidare & $\begin{array}{l}\text { levantar-se } \\
\text { [da mesa] (?) }\end{array}$ & banunchan & bangunkan & \\
\hline $26 I$ & Buona sera! & boa tarde & sabalchaer & çabâh al-khayr (A) & ${ }_{131}$ \\
\hline 262 & $\mathrm{Al}$ risponder & ao responder[-lhe] & chaer saudar & $\begin{array}{l}\text { khayr }(A) \text {, saudara } \\
(\mathrm{S}) !\end{array}$ & ${ }_{132}^{2}$ \\
\hline 263 & $\mathrm{Al}$ dare & dar & minta & minta & 133 \\
\hline 264 & A dar ad alguno & $\begin{array}{l}\text { dar [pancada] a } \\
\text { alguém }\end{array}$ & bripocol & beri pukul & \\
\hline
\end{tabular}

125 À letra «cobertura da cabeça, tampa da cabeça». Em português de Timor usa-se para o chapéu de palha aproximadamente cónico, ou em forma de chapéu colonial, o empréstimo malaio tudom.

${ }^{126}$ Kata significa «palavra»; para «dizer» usa-se a forma derivada berkata; «falar» (intransitivo) diz-se cakap, bercakap.

${ }^{127}$ Sana de per si significa, «ali, acolá», datang significa «vir» ou «vem!».

${ }^{128}$ Lit., em árabe, «a paz esteja sobre vós»; a resposta é «e sobre vós esteja a paz».

129 Lit. «vinde, orancaias, comer» ou «vamos, meus senhores, comer».

${ }_{330}$ De facto, a frase significa «olha para nós, homem!».

${ }^{131}$ A significação da frase está trocada: em árabe çabâh al khayr significa «manhã próspera», portanto «bom dia» e não «boa tarde».

${ }^{132}$ Lit. «boa, primo!».

${ }^{133}$ Minta não significa «dar», mas «pedir». 


\begin{tabular}{|c|c|c|c|c|c|}
\hline 265 & A li cepi di fero & $\begin{array}{l}\text { corrente, cepo, } \\
\text { algema }\end{array}$ & balanghu & belenggu & \\
\hline 266 & O, como puza! & $\begin{array}{l}\text { ó, como fede! que } \\
\text { mal cheira! }\end{array}$ & bossochini & busuk ini! & 134 \\
\hline 267 & $\mathrm{Al}$ homo iovene & homem jovem & horan muda & orang muda & \\
\hline 268 & Al vechio & velho & tua & tua & \\
\hline 269 & Al scrivano & escrivão & xiritoles & juru tulis & 135 \\
\hline 270 & A la carta & papel & cartas & kertas (A) & 136 \\
\hline $27 \mathrm{I}$ & Al scrivere & escrever & magnurat & menyurat & \\
\hline 272 & A la penna & pena & calam & kalam (A) & \\
\hline 273 & $\mathrm{Al}$ inchiostro & tinta & dauat & dawat & \\
\hline 274 & Al calamaro & tinteiro & padautan & pedawatan & \\
\hline 275 & La letera & carta & surat & surat & \\
\hline 276 & Non lo ho & não o tenho & guala & wala & 137 \\
\hline 277 & Vien qui & vem aqui! & camari & ke mari! & \\
\hline 278 & Che voletti & que quereis? & appa mau & $\begin{array}{l}\text { apa mahu, apa } \\
\text { mau? }\end{array}$ & \\
\hline 279 & Che mandati & que mandais? & appa ito & apa itu? & ${ }_{138}^{8}$ \\
\hline 280 & $\mathrm{Al}$ porto de mare & porto de mar & labuan & labuhan & \\
\hline $28 \mathrm{I}$ & A la galia & galé & gurap & gurab, ghurab $(\mathrm{A})$ & \\
\hline 282 & A la nave & navio & capal & kapal (T) & \\
\hline 283 & A la proa & proa & allon & haluan & \\
\hline 284 & A la popa & рора & biritan & buritan & \\
\hline 285 & Al navigare & navegar & belaiar & berlayar, belayar & \\
\hline 286 & $\mathrm{Al}$ suo arbore & sua árvore (mastro) & tian & tiang & \\
\hline 287 & $\mathrm{Al}$ antena & mastro, verga & laiar & layar & 139 \\
\hline 288 & Alle sartie & enxárceas & tamira & tembérang & \\
\hline 289 & A la vella & vela & leier & layar & \\
\hline 290 & A la gabia & gávea & simbulaia & simpul layar (?) & $14^{\circ}$ \\
\hline
\end{tabular}

134 Lit. «fede, isto!».

135 À letra «perito» (juru) «em escrever»(tulis).

136 O termo arábico é o étimo do português cartaz.

137 Wala significa «não é, não há», mas em tagalo.

${ }_{13}^{8}$ Apa hitu significa na realidade «que é isso?», ou «que é aquilo?».

139 Layar significa «vela» e não «mastro», contemplado aliás na entrada precedente. Para «verga» há o composto pebahu layar, lit. «que faz de braço à vela».

${ }^{140}$ A reconstituição de Bausani, simpul layar, «amarrar as velas, prender as velas» parece-nos de facto, a única plausível, embora o significado não concorde. Gávea tem dois 


\begin{tabular}{|c|c|c|c|c|c|}
\hline $29 \mathrm{I}$ & $\begin{array}{l}\text { A la corda del } \\
\text { ancora }\end{array}$ & cabo da âncora & danda & dandan & ${ }^{141}$ \\
\hline 292 & A la anchora & âncora & sau & sauh & \\
\hline 293 & Al batello & batel & sampan & sampan & 142 \\
\hline 294 & $\mathrm{Al}$ remo & remo & daiun & dayung & 143 \\
\hline 295 & A la bombarda & bombarda & badil & bedil (T) & 144 \\
\hline 296 & $\mathrm{Al}$ vento & vento & anghin & angin & \\
\hline 297 & $\mathrm{Al}$ mare & mar & laut & laut & \\
\hline 298 & Huomo, vien qui! & homem, vem cá! & horan itu dantan & orang itu, datang! & \\
\hline 299 & A li sui pugnali & $\begin{array}{l}\text { seus punhais } \\
\text { (crizes) }\end{array}$ & calix, golog & keris, golok & 145 \\
\hline 300 & Al suo manicho & $\begin{array}{l}\text { sua manga, seu } \\
\text { punho }\end{array}$ & daganan & $\begin{array}{l}\text { pegangan, gagang } \\
\text { (?) }\end{array}$ & 146 \\
\hline 301 & A la spada & espada & padan gole & pedang, golok & \\
\hline 302 & A la zarabotana & zarabatana & sumpitan & sumpitan & \\
\hline 303 & A le sua freze & suas frechas & damach & damak & \\
\hline
\end{tabular}

sentidos: etimologicamente significa «gaiola, jaula», e daí, «cesto da gávea», colocado acima da primeira vela do mastro principal como posto de observação; daí se passou ao sentido de «vela vizinha do cesto», «segunda vela do mastro-grande, acima do papafigos».

${ }^{{ }^{14} \mathrm{I}}$ Dandan significa «amarra, cabo, corda, cordame», em geral, não necessariamente «cabo da âncora».

${ }^{142}$ O termo é, segundo as investigações mais fidedignas, de origem cambojana, derivado do khmer sãmpan; a etimologia geralmente apresentada, que o faz vir do cantonense 三板 sam pan, «três tábuas» deve-se certamente a paronímia; de qualquer modo a grafia normal em chinês não é 三板, mas 舢舨, que se lê em mandarim shan pan: cf. L. Aurousseau (I922), «Le mot sampan est-il chinois?», Bulletin de l'École Française d'Extrême-Orient, XXII, p. I40.

${ }^{143}$ Dayung é «remo» ou «pedal» em geral, designando sobretudo o remo fixo ao casco da embarcação; mas usa-se em Java para também para o pangaio ou remo de uma só pá que se segura com as mãos ambas, dito em geral kayuh, pengayuh ou kemayuh; é de pengayuh, que vem o português pangaio ou pangaia, com cuja etimologia Mons. Dalgado (I9I9-I92I) não atinou.

${ }^{144}$ Bedil, usado sobretudo em Java e em Samatra, designa a «arma de fogo» em geral; mas ao tempo as armas de fogo ligeiras eram ainda raras, e é talvez por isso que vieram a ser geralmente designadas pelo empréstimo holandês senapan.

${ }^{145}$ O punhal malaio ou criz, de folha em geral serpentiforme, é keris; golok é mais uma «faca de mato», de folha larga e gume geralmente convexo.

${ }^{146}$ Pegangan, «pega, punho, cabo» (de pegang, «pegar, segurar») parece-nos tão lógico e foneticamente possível como gagang, «caule, pega, manga» que Bausani sugere. 


\begin{tabular}{|c|c|c|c|c|c|}
\hline 304 & $\mathrm{Al}$ erba venenata & erva envenenada & урu & ipuh & 147 \\
\hline 305 & Al carchasso & carcás, aljava & bolo & buluh & $14^{8}$ \\
\hline 306 & $\mathrm{Al}$ archo & $\operatorname{arco}$ & bossor & busur & \\
\hline 307 & A le sue freze & suas frechas & anacpana & anak panah & 149 \\
\hline 308 & A li gati & gatos & cochin puchia & kucing, pusa & 150 \\
\hline 309 & Al sorge & rato & ticus & tikus & \\
\hline 310 & $\mathrm{Al}$ legoro & crocodilo & buaia & buaya & \\
\hline 3II & $\begin{array}{l}\text { A li vermi che } \\
\text { mangiano le navi }\end{array}$ & gusano & capan lotos & kapang, lotos & ${ }_{151}$ \\
\hline $3^{12}$ & Al hamo da pescara & anzol & matacauir & mata kail & 152 \\
\hline 313 & A la sua esca & isca & unpan & umpan, empan & \\
\hline 314 & A la corda del hamo & linha de pesca & tunda & tunda & 153 \\
\hline 315 & $\mathrm{Al}$ lavare & lavar & mandi & mandi & 154 \\
\hline 316 & Non haver paura & não tenhas medo! & jangan tacut! & jangan takut! & \\
\hline 317 & Straca & grande cansaço & lala & lelah & \\
\hline $3^{18}$ & Uno baso dolce & um beijo doce & sadap manis & sedap manis & 155 \\
\hline 319 & $\mathrm{Al}$ amico & amigo & saudara & saudara $(\mathrm{S})$ & 156 \\
\hline 320 & Al nemicho & inimigo & saubat & sobat $(\mathrm{A})$ & 157 \\
\hline $32 \mathrm{I}$ & Certo hè & certo é & zonghu & sungguh & \\
\hline 322 & Al marcadantre & mercadejar, tratar & biniaga & berniaga $(\mathrm{S})$ & ${ }_{158}$ \\
\hline
\end{tabular}

${ }^{147}$ Ipuh significa simplesmente «veneno».

${ }^{14^{8}}$ Buluh significa simplesmente «bambu», mas as mais das vezes era um troço de bambu que se usava como aljava.

149 Lit. «filhos do arco» (panah, equivalente a busur ou busar).

${ }_{150}$ Kucing é o termo corrente em malaio; puchia pode representar o tagalo ou o dayak pusa, equivalente ao tétum busa, «gato».

${ }^{151}$ Kapang é o nome malaio; lotos é tagalo. O nome científico do bichinho é Teredo navalis, L.

${ }^{152}$ Lit. «olho da cana de pesca».

153 Tunda em malaio significa «rebocar, içar»; no sentido de «linha de pesca» usa-se, segundo Bausani, em bissaia.

${ }^{154}$ Mandi em rigor é «tomar banho, banhar-se»; lavar in genere diz-se cuci.

155 Manis significa de facto «doce», mas sedap significa «agradável, gostoso, delicioso, bem-cheiroso».

${ }^{156}$ Cf. supra o vocábulo ${ }^{\circ}{ }^{1} 4$.

157 Sobat, variante de sahabat, significa na realidade «amigo, camarada»; «inimigo» diz -se musuh ou seteru (S).

${ }_{15} 8$ Étimo do português veniaga. 


\begin{tabular}{|c|c|c|c|c|c|}
\hline 323 & Non ho & não tenho & auis & habis & 159 \\
\hline 324 & A essere amico & ser amigo & pugna & punya & 160 \\
\hline 325 & Due cose & duas coisas & maluphp & $?$ & \\
\hline 326 & $\mathrm{Si}$ & $\operatorname{sim}$ & ouo & $\mathrm{au}$ & 161 \\
\hline 327 & Al rufo & rufião, alcoviteiro & zoroan, pagnoro & suruhan, penyuruh & 162 \\
\hline 328 & A darce piacer & dar-se ao prazer & mamain & memain & 163 \\
\hline 329 & A essere agrizato & $\begin{array}{l}\text { estar azedo, irado } \\
\text { (?) }\end{array}$ & mala & marah, amarah & \\
\hline 330 & $\mathrm{Al}$ mato & doido & gila & gila & \\
\hline $33 \mathrm{I}$ & $\mathrm{Al}$ interprete & intérprete & giorobaza & juru bahasa & 164 \\
\hline 332 & Quanti lingagi sai? & $\begin{array}{l}\text { quantas línguas } \\
\text { sabes? }\end{array}$ & barapa bahas tau & $\begin{array}{l}\text { berapa bahasa } \\
\text { tahu? }\end{array}$ & \\
\hline 333 & Molti & muitos /-as & bagna & banyak & \\
\hline 334 & $\begin{array}{l}\text { Al parlare de Ma- } \\
\text { laca }\end{array}$ & ao falar de Malaca & chiara malaiu & cara melayu & 165 \\
\hline 335 & Dove sta cului? & onde está aquele? & dimana horan? & dimana orang [itu]' & \\
\hline 336 & A la bandiera & bandeira & tonghol & tunggul & 166 \\
\hline 337 & Adesso & agora & sacaran & sekarang & \\
\hline $33^{8}$ & Da matina & de manhã & hezoch & ésok & 167 \\
\hline 339 & L'altro giorno & $\begin{array}{l}\text { outro dia, passado } \\
\text { amanhã }\end{array}$ & luza & lusa & \\
\hline
\end{tabular}

159 Habis significa na realidade «acabou-se, gastou-se».

160 Punya é forma abreviada de empunya, «seu dono», mas através de frases do tipo rumah ini saya (em) punya, lit. «esta casa eu seu dono, i. e., esta casa é minha», tornou-se um verbo com o sentido de «possuir» e, sobretudo em «malaio de bazar» uma espécie de índice do genitivo (v. g.: saya punya bini, «a minha mulher»). Não envolve qualquer sentido de amizade.

${ }^{161} A u$, «sim» é forma dialectal usada em Brunei e Sarawak; cf. supra vocábulo nº i99.

${ }_{162}$ Tanto penyuru como suruhan se ligam à $V_{\text {suruh }}$, "pedir», o primeiro como nomen agentis o segundo com nomen rei actae.

${ }_{163}$ Main significa «brincar, jogar, tocar (um instrumento)»; mas pode, eufemisticamente, aludir a «comércio carnal».

${ }^{164}$ Lit. «perito (juru) em língua» (bahasa), étimo do português jurubaça; a variante dur$b a c ̧ a$, usada em Timor, vem por intermédio do tétum, língua em que não existe o fonema $j$.

165 Lit. «ao modo malaio, à maneira malaia, à chara malaia».

${ }^{166}$ Tunggul significa «tronco, toco, pau» e, aparentemente por extensão, «estandarte, bandeira»; para «bandeira» usa-se hoje mais o empréstimo português bendéra.

${ }^{167}$ Em malaio clássico ésok significa «manhã» e bésok, «amanhã»; hoje usam-se ambos os termos neste derradeiro sentido, preferindo-se para «manhã» o termo pagi. 


\begin{tabular}{|c|c|c|c|c|c|}
\hline 340 & Hieri & ontem & calamari & kelmarin, kemarin & \\
\hline $34 \mathrm{I}$ & $\mathrm{Al}$ martelo & martelo & palmocol basi & pemukul besi & 168 \\
\hline 342 & Al chiodo & prego & pacu & paku & \\
\hline 343 & $\mathrm{Al}$ mortaro & pilão, gral, almofariz & lozon & lesun & \\
\hline 344 & Al pilone de pistare & pilão, mão do gral & atan & antan & \\
\hline 345 & Al balare & bailar & manari & menari, tari & \\
\hline 346 & $\mathrm{Al}$ pagare & pagar & baiar & bayar & \\
\hline 347 & Al chiamare & chamar & panghil & panggil & \\
\hline 348 & $\begin{array}{l}\text { A non essere } \\
\text { maritato }\end{array}$ & ser solteiro & ugan & ujang, bujang & 169 \\
\hline 349 & A essere maritato & ser $\{$ já\} casado & sudah babini & $\{$ sudah $\}$ berbini & \\
\hline $35^{\circ}$ & Tuto uno & tudo junto & samua & semua & \\
\hline $35 \mathrm{I}$ & A la piogia & chuva & ugian & hujan & \\
\hline 352 & Al ebriaco & ébrio, bêbedo & moboch & mabuk & \\
\hline 353 & A la pelle & pele & culit & kuit & \\
\hline 354 & A la bissa & bicha, lagarta & ullat & ulat & \\
\hline 355 & $\mathrm{Al}$ conbater & combater & guzar & gusar & 170 \\
\hline 356 & Dolce & doce & manis & manis & \\
\hline 357 & Amaro & amargo & azon & asam & ${ }^{171}$ \\
\hline $35^{8}$ & Como stai? & como estás? & appa giadi & apa jadi & ${ }^{172}$ \\
\hline 359 & Benne & bem & bay & baik & \\
\hline 360 & Malle & mal & sachet & sakit & 173 \\
\hline $36 \mathrm{I}$ & Portame quello & traze-me aquilo & biriacan & beri akan... & 174 \\
\hline
\end{tabular}

${ }_{168}$ Lit. «batedor de ferro»; também se diz tukul e palu.

${ }^{169}$ Hoje o termo usual é bujang; ujang é dialectal, usado em Sunda (Java ocidental).

${ }^{170}$ Em rigor, gusar não significa «combater», mas «irar-se, encolerizar-se, estar furioso».

${ }_{171}$ Em rigor, asam, que é também o nome do tamarindo, não significa «amargo» mas «ácido»; «amargo» diz-se mais propriamente pahit; mas, como em outras línguas, há uma certa osmose entre as duas noções.

${ }^{172}$ Apa jadi, significa mais exatamente «que sucedeu? que se passa?» ou, quando muito, «que te tornas tu?».

${ }_{173}$ Em rigor sakit significa «doente, dorido».

174 Beri significa «dar» e não exatamente «trazer»; de qualquer modo a frase está incompleta pois akan, que significa "para, para com, em relação a», é uma preposição que queda sem regime; mas beri, «dar», onstrói-se normalmente com kepada, «a, para»; deveria portanto ser algo como beri \{barang itu\} kepadaku, «dá-me \{aquela coisa\}». A forma benefactiva do mesmo verbo é (mem) berikan, «dar a, dar para», mas a transcrição dada por Pigafetta corresponde mais a beri akan que a berikan. 


\begin{tabular}{|c|c|c|c|c|c|}
\hline 362 & $\begin{array}{l}\text { Questo huomo hè } \\
\text { un poltrone }\end{array}$ & $\begin{array}{l}\text { este homem é um } \\
\text { poltrão }\end{array}$ & $\begin{array}{l}\text { giadi hiat horan } \\
\text { itu }\end{array}$ & $\begin{array}{l}\text { jadi kiat (?) orang } \\
\text { itu }\end{array}$ & 175 \\
\hline 363 & Basta & basta & suda & sudah & 176 \\
\hline \multicolumn{6}{|c|}{ I venti (Os ventos) } \\
\hline 364 & A la tramonana & norte & iraga & hilaga & 177 \\
\hline 365 & Al mezo dì & sul & salatan & selatan & \\
\hline 366 & Al levante & $\begin{array}{l}\text { levante, oriente, } \\
\text { leste }\end{array}$ & timor & timur & \\
\hline 367 & $\mathrm{Al}$ ponente & $\begin{array}{l}\text { poente, ocidente, } \\
\text { oeste }\end{array}$ & baratapat & barat tepat & 178 \\
\hline 368 & Al griego & nordeste & utara & utara $(\mathrm{S})$ & 179 \\
\hline 369 & $\mathrm{Al}$ garbin & sudoeste & berdaia & barat daya & \\
\hline 370 & Al maestrale & noroeste & barolaut & barat laut & \\
\hline $37 \mathrm{I}$ & $\mathrm{Al}$ siroco & sueste & tunghara & tenggara & \\
\hline \multicolumn{6}{|c|}{ Número (Números) } \\
\hline 372 & uno & um & satus & satu & \\
\hline 373 & dui & dois & dua & dua & \\
\hline 374 & tre & três & tiga & tiga & \\
\hline 375 & catro & quatro & ampat & empat & \\
\hline 376 & cinque & cinco & lima & lima & \\
\hline 377 & sey & seis & anam & enam & \\
\hline $37^{8}$ & sette & sete & tugu & tijuh & \\
\hline 379 & octo & oito & duolapan & delapan & 180 \\
\hline
\end{tabular}

${ }^{775}$ Hiat não é registado pelos dicionários; o termo mais próximo é kiat, «rígido, inerte, dormente», que se diz de um membro do corpo, de modo que a frase faz pouco sentido. Poderia ser por exemplo: jadi ketakutan orang itu, lit. «ficou tomado de medo aquele homem!», ou penakut orang itu, «é medroso aquele homem!».

${ }^{176}$ Sudah significa «já»; mas por elipse (v. g. por sudah cukup, «já é suficiente, já basta») pode, de facto, significar «basta!». O Glossário Chinês-Malaio dá, num contexto de vocábulos tocantes a cerimónias e audiências régias, 蘇答 su-ta como equivalente a «fim da cerimónia».

${ }^{177}$ É o termo tagalo para «norte»; em malaio corrente diz-se utara; o Glossário Chinês-Malaio reflete o uso comum ao transcrever laut besar utara, «grande mar do norte» por 澇不撒烏答刺 lao pu-sa wu-ta-la.

${ }_{178}$ Tepat significa «preciso, exato» e é desnecessário aqui.

${ }_{179} \mathrm{O}$ uso de utara para significar «nordeste» em vez de «norte» é, segundo Bausani, dialectal, próprio de Brunei; aliás diz-se timur laut (lit. «oriente-mar»).

I80 A forma hoje corrente é delapan; mas em textos antigos ocorre a forma etimológica dualapan, i. e., «dois (dua) roubados (alap) [a dez] + sufixo (an)»; o Glossário Chinês-Malaio 


\begin{tabular}{|c|c|c|c|c|c|}
\hline 380 & nove & nove & sambilan & sembilan & \\
\hline $3^{8 \mathrm{I}}$ & diece & dez & sapolo & sepuluh & \\
\hline 382 & vinti & vinte & duapolo & duapuluh & \\
\hline 383 & trenta & trinta & tigapolo & tigapuluh & \\
\hline 384 & quaranta & quarenta & ampatpolo & empatpuluh & \\
\hline 385 & cinquanta & cinquenta & limapolo & limpuluh & \\
\hline 386 & sexanta & sessenta & anampolo & enampuluh & \\
\hline 387 & settanta & setenta & tugupolo & tujuhpuluh & \\
\hline 388 & octanta & oitenta & dualapanpolo & delapanpuluh & \\
\hline 389 & novanta & noventa & sambilanpolo & sembilanpuluh & \\
\hline 390 & cento & cem & saratus & seratus & \\
\hline $39 \mathrm{I}$ & duzendo & duzentos & duaratus & dua ratus & \\
\hline 392 & trecento & trezentos & tigaratus & tiga ratus & \\
\hline 393 & quatrocento & quatrocentos & anamparatus & enam ratus & \\
\hline 394 & cinquecento & quinhentos & limaratus & lima ratus & \\
\hline 395 & seycento & seiscentos & anambratus & enam ratus & \\
\hline 396 & setecento & setecentos & tugurattus & tujuh ratus & \\
\hline 397 & otocento & oitocentos & dualapanrattus & delapan ratus & \\
\hline 398 & novecento & novecentos & sambilanratus & sembilan ratus & \\
\hline 399 & mille & mil & salibu & seribu & \\
\hline 400 & due millia & dois mil & dualibu & dua ribu & \\
\hline $40 \mathrm{I}$ & tre millia & três mil & tigalibu & tiga ribu & \\
\hline 402 & quatro mille & quatro mil & ampatlibu & empat ribu & \\
\hline 403 & cinque millia & cinco mil & limalibu & lima ribu & \\
\hline 404 & sey millia & seis mil & anamlibu & enam ribu & \\
\hline 405 & sette millia & sete mil & tugulibu & tujuh ribu & \\
\hline 406 & octo millia & oito mil & dualapanlbu & delapan ribu & \\
\hline 407 & nove millia & nove mil & sanbilanlibu & sembilan ribu & \\
\hline 408 & diece millia & dez mil & salacza & selaksa $(\mathrm{S})$ & 181 \\
\hline
\end{tabular}

tem 都刺板 tu-la-pan. As demais línguas autronésicas (jau, tagalo, tétum, etc.) conservam a forma antiga (wolu, waló, walu, etc.). O mesmo se passa com o número «nove»: o malaio tem sembilan, i. e. «um (se-), levado (ambil) [a dez] + sufixo (an)», mas o jau, o tagalo e o tétum têm respectivamente sanga, siyám e sia.

${ }^{18}$ É interessante notar que o étimo sanscrítico deste termo, lakṣa (que através do prácrito lakha e do neo-árico lakh, deu em português laque) significa «cem-mil», mas veio a significar em malaio apenas «dez-mil». 


\begin{tabular}{|c|c|c|c|c|}
\hline 409 & vinti millia & vinte mil & dualacza & dua laksa \\
\hline 410 & trenta millia & trinta mil & tigalacza & tiga laksa \\
\hline $4 \mathrm{II}$ & quaranta millia & quarenta mil & ampatlacza & empat laksa \\
\hline 412 & cinquanta millia & cinquenta mil & limalacza & lima laksa \\
\hline 413 & sesanta millia & sessenta mil & anamlacza & enam laksa \\
\hline 414 & settanta millia & setenta mil & tugulacza & tujuh laksa \\
\hline 415 & octanta millia & oitenta mil & dualapanlacza & delapan laksa \\
\hline 416 & novanta millia & noventa mil & sambilalacza & sembilan laksa \\
\hline 417 & cento mille & cem mil & sacati & seketi $(\mathrm{S})$ \\
\hline 418 & duecento mille & duzentos mil & duacati & dua keti \\
\hline 419 & trecento millia & trezentos mil & tigacati & tiga keti \\
\hline 420 & quatrocento millia & quatrocentos mil & ampatcati & empat keti \\
\hline $42 \mathrm{I}$ & $\begin{array}{l}\text { cinquecento } \\
\text { millia }\end{array}$ & quinhentos mil & limacati & lima keti \\
\hline 422 & seycento millia & seiscentos mil & ampatcati & enam keti \\
\hline 423 & setecento millia & setecentos mil & tugucati & tujuh keti \\
\hline 424 & octocento millia & oitocentos mil & dualapancati & delapan keti \\
\hline 425 & novecento millia & novecentos mil & sambilancati & sembilan keti \\
\hline 426 & $\begin{array}{l}\text { diece fiate cento } \\
\text { millia }\end{array}$ & dez vezes cem mil & saiuta & sejuta $(S)$ \\
\hline 427 & \multicolumn{4}{|c|}{$\begin{array}{l}\text { Tucti li cento, li mille, li diece mille, li centi mille } \\
\text { et diece fiate cento mille se congiungenno con il numero } \\
\text { de satus et dua etc. }\end{array}$} \\
\hline & & \multicolumn{3}{|c|}{$\begin{array}{l}\text { Todos os centos, mil, dez mil, cem mil e dez vezes } \\
\text { cem mil se conjungem com os números satus, dua, etc. }\end{array}$} \\
\hline
\end{tabular}

\section{REFERÊNCIAS BIBLIOGRÁFICAS}

AdelaAr, K. A. (i994). «Malay and Javanese Loan-words in Malgasy, Tagalog and Siraya (Formosa)». Bijdragen tot de Taal-, Land-en Volkenkunde, I50- I, 50-65. Amarasinha (I839-I845). Amarasinha, Amarakocha ou Vocabulaire, avec une traduction française par A. Loiseleur Deslongchamps. París: Imprimerie Royale, 2 v.

Andili, A. Bahar (1978-1979). «Profil Daerah Maluku Utara» in E. K. M. Masinambouw, Halmahera dan Raja Ampat, vol. I. Indonesian Journal of Cultural Studies. Majalah Ilmu-ilmu Sastra Indonesia, VIII-I, nomor istimewa I [ $\mathrm{n}^{\circ}$ especial I], junho I978/1979 [sic], 3-I5.

Bausani, Alessandro (i960). «The First Italian-Malay Vocabulary by Antonio Pigafetta». East and West, II-4, 229-248. 
Beg, M. A. J. (1977). Arabic Loan-Words in Malay. A Comparative Study. Kuala Lumpur: University of Malaya Press.

Corominas, Joan; Pascual, José A. (I987-I99i). Diccionario Crítico Etimológico Castellano e Hispánico. Madrid: Gredos, 6 v.

Cortelazzo, Manillo; Zolli, Paolo (1979). Dizionario etimologico delle Lingua Italiana. Bolonha: Zanichelli, I979, 5 v.

Cribb, Robert (2000). Historical Atlas of Indonesia. Londres; Singapura: Curzon \& New Asian Library.

Dalgado, Mons. Sebastião Rodolfo (I919-I92i). Glossario Luso-Asiático. Coimbra: Imprensa da Universidade; Academia das Sciências de Lisboa, 2 v.

Edwards, E. D.; Blagden, C. O. (i93I). «A Chinese Vocabulary of Malacca Malay Words and Phrases, collected between A. D. I403 and I5I I». Bulletin of the School of Oriental Studies, 6-3, 715-749.

Gonda, J. (1998). Sanskrit in Indonesia. Nova Delhi: International Academy of Indian Culture; Aditya Prakashan

Lombard, Denys; Arifin, Winarsih; Wibisono, Minnie (i970). Le «Spraeck Ende Woord-Boek» de Frederick de Houtman. Première méthode de malais parlé (fin du $X V I^{e}$ s.). París: École Française d'Extrême-Orient.

Lombard, Denys; Thomaz, Luís Filipe F. R. (I98I). «Remarques préliminaires sur un lexique portugais-malais inédit de la Bibliothèque Nationale de Lisbonne». Nigel Phillips; Khaidir Anwar (eds.), Papers on Indonesian Languages and Literatures. Londres: School of Oriental and African Studies.

Munoz, Paul Michel (2006). Early Kingdoms of the Indonesian Archipelago and the Malay Peninsula. Singapura: Éditions Didier Miller, 236-239.

Postma, Anton (1992). «The Laguna copper-plate inscription», Philippine Studies, 40-II, I83-203.

Thomaz, Luís Filipe F. R. (I994). «A escravatura em Malaca no século XVI». Studia, 53, 253-316.

Thomaz, Luís Filipe F. R. (2003). «As cartas malaias de Abu Hayat, sultão de Ternate, a El-Rei de Portugal e os primórdios da presença portuguesa em Maluco». Anais de História de Além-Mar, 4, 38I-446.

Tryon, Darrell T. (dir.) (r995). Comparative Austronesian Dictionary: an introduction to Austronesian studies. Berlín; Nova York: Moton de Gruyter, 5 v. 